\title{
Richard Bambridge
}

\author{
THE ROLE OF TONIC NEURAL ACTIVITY
}

IN MOTIVATIONAL PROCESSES

\begin{abstract}
The multi-unit recording technique was used to study the activity of neuron populations in various brain locations in cats during long, natural behaviour sequences in a free behavioural situation. Electroencephalographic (EEG) records were also obtained from each recording site. The total multi-unit activity
\end{abstract} levels in many of these areas, including parts of the cortex, thalamus and reticular formation, tended to co-vary, and these variations in tonic activity were associated with the observed behavioural arousal leve1 of the cat. Variations in tonic activity in cher areas (1ateral geniculate nucleus and inferior colliculus) were shown to be more reliably correlated with specific sensory input than with arousal levels. Behavioural arousal levels appear to be more closely related to tonic neural activity in many areas of the brain than to the EEG record. The neural bases of specific-center and drive arousal theories of motivation are examined in the light of these data. 


\section{THE ROLE OF TONIC NEURAL ACTIVITY}

\section{IN MOTIVATIONAL PROCESSES}

\section{by}

Richard Bambridge

A thesis submitted to the Faculty of Graduate Studies and Research in partial fulfilment of the requirements for the degree of Doctor of Philosophy.

Department of Psychology

McGill University

Apri1 1968

Montreal.

(C) Richard Bambridge 1969 


\section{ACKNOWLEDGMENTS}

I wish to thank Dr. Ronald Melzack for his support, advice and encouragement throughout al1 phases of this research, and in the preparation of this thesis.

I would like also to thank Mr. Kare1 Gijsbers for many fruitful discussions, and Mr. Joseph Vanagas for his patient technical advice and assistance. 
TABLE OF CONTENTS

Page

INTRODUCTION. . . . . . . . . . . . . . 1

General and Specific Motivational Mechanisms . . . 2

Physiological Mechanisms . . . . . . . . 7

Measures of Arousal. ............... 9

Multi-unit Measures and Sensory Systems.......16

Arousal and Tonic Activity . . . . . . . . . 19

Purpose of the Present Study ...........23

METHODS . . . . . . . . . . . . . . 26

Subjects ................... 26

Surgica1 Procedure ...............26

Electrodes ................... 27

Recording Equipment. .............. 27

Artifact in Multi-unit Records ......... 30

Procedure. . .................30

Histology. . . . . . . . . . . . . 33

RESULTS . . . . . . . . . . . . 34

Relationships between Multi-unit

and EEG Recordings. ............ 35

Bursting. . . . . . . . . . . 35

Post Reinforcement Synchrony. . . . . . . 36

Anesthesia. . . . . . . . ... 36

EEG Synchrony and Desynchrony ....... 37

Tonic Activity and Behavioural Arousal ...... 38

Arousal-related Areas . . . . . . . . 38

Tonic Activity in Sensory Nuclei....... 42

Sleep. . . . . . . . . . . . . 44

DISCUSSION. . . . . . . . . . . . 4 48

SUMMARY . . . . . . . . . . . . . . 60

REFERENCES. . . . . . . . . . . ...61

TABLE . . . . . . . . . . . . . . 70

FIGURES . . . . . . . . . . . . . . . 71

APPENDIX ..................... 


\section{INTRODUCTION}

Theoretical treatments of the problem of emotional and motivational mechanisms in psychology have characteristically tended toward two extremes. One tendency is to suggest a simplified unidimensional mechanism, such as Hull's (1943) general drive, Hebb's (1955) drive-arousal hypothesis, or even, in general terms, Freud's libidinous energy. The second approach is the postulation of separate mechanisms to deal with each emotional or motivational category, such as hunger or anger, sexual behaviour or jealousy. McDougal1 (1923) proposed that an instinct governs each such class of behaviour. Similar $1_{y} y$, Morgan, (1943, 1957) postulated a number of central motive states each controlling a certain aspect of motivation--a view which is closely related to Stellar's (1954) proposal that motivated behaviour is controlled by pairs of hypothalamic centres, each pair approximately filling the role of a central motive state. This schism remains a central problem in understanding motivation and, as the above examples illustrate, transcends major divisions in theoretical psychology, such as physiological and non-physiological approaches. In this introduction, the nature of the problem will be outlined, 
and data will be reviewed to indicate common grounds for both views.

General and Specific Motivational Mechanisms

Problems are encountered when attempts are made to extend either the general or the specific approach into a broad theoretical system, and accounts of motivational phenomena which are more concerned with facts than with theoretical rigour tend to avoid the problem of a theoretical synthesis by treating general and specific aspects of motivation separately (e.g. Woodworth and Schlosberg, 1955; Duffy, 1962; Hinde, 1966). The main problem encountered by MacDouga11's instinct approach, and subsequently by Morgan's concept of central motive states and Ste1lar's hypothalamic centres theory, was the way in which the number of instincts or physiological mechanisms proliferate as more aspects of behaviour are considered, or as a particular aspect is analysed in detail. Morgan (1957) recognizes this problem; with regard to the mechanisms underlying food acceptance, for instance, he admits that we may have to assume a dozen or more hunger drives which must be arbitrarily combined in order to talk about hunger in general. This proliferation of instincts or central motive states, and the necessity 
for arbitrarily grouping them into behaviourally meaningful units, clearly undermines the theoretical power of such systems. Moreover, the approach becomes less plausible physiologically as increasingly complex aspects of behaviour are considered. These theories also fail to make any provision for learning and perceptual phenomena, which imposes marked limitations on their general psychological value.

Hul1 (1943) and Hebb (1955) avoided these problems by assuming one general drive underlying an intensity dimension of motivation, and accounted for qualitative differences in motivational states (as between humger and thirst) in terms of perceptual and learning mechanisms. One of the limitations of Hull's theory, however, was that his general drive could be aroused only by homeostatic imbalances in the body. In contrast, Hebb's "drive" could be aroused not only by interoceptive stimuli arising from homeostatic imbalances, but also by sensory input per se, and by particular patterns of cortical activity, which were in turn dependent on the past experience of the organism. This concept of drive was flexible enough to cope with the problem raised by motivational phenomena such as exploration (Butler, 1953; 
Butler and Harlow, 1954) problem seeking (Havelka, 1956) and irrational fears (Kohler, 1925; Melzack, 1952; Hebb, 1953) which seemed to have no relation to bodily needs. The theory had the additional advantage of a plausible neural mechanism, based on the discovery of the activating action of the reticular formation on the cortex and on motor systems (Moruzzi and Magoun, 1949; Schrener, Lindsley and Magoun, 1949).

One of the major differences between the positions of Morgan or Steller and Hebb, is the proposed location of neural processes subserving qualitative motivational differences. While Stellar (1954) regarded the activity of specific localised hypothalamic centres as the neural basis of specific motivational tendencies, Hebb relegated such functions to the cortex. The hypothalamic mechanisms which Stellar considered to be the wellsprings of motivation were demoted to the role of motor centres controlling the execution of such activities as eating and drinking, but were not considered to be responsible for the arousal, maintenance or termination of such behaviours. Although this gave Hebb's theory much more generality and explanatory power as a behavioural theory, the experimental evidence in support of Stellar's position cannot be so easily dismissed. This evidence derives 
mainly from studies of the behavioural effects of electrical stimulation or lesions in the hypothalamus.

It is evident from early work in this field by Hess (summarized in Hess, 1957) that in some instances electrical stimulation of the appropriate hypothalamic areas does not directly produce stimulus-bound motor patterns, but lowers the threshold for the elicitation of such patterns by the appropriate stimuli (such as an object to attack). More recent work has shown that animals will actively seek out such stimuli, and learn tasks such as lever pressing or maze running, in order to reach them. Thus, Andersson and Wyrwicka (1957) showed that watersatiated goats, in response to stimulation of the periventricular hypothalamus would climb a flight of steps to reach water and drink. Similar1y, food-satiated rats will learn to press a bar (Coons, Levak and Miller, 1965) or run a T-mazé (Mende1son and Chorover, 1965) to obtain food when the lateral hypothalamus is electrically stimulated. These experiments demonstrate that states evoked by hypothalamic stimulation have much in common with normal motivational states, and indicate that subcortical mechanisms play an important role in motivational processes, much more important, at least, than the co-ordination of movements 
involved in the expression of such states. Hebb (1958) has acknowledged the power of such arguments by admitting the plausibility of qualitative changes within the arousal dimension. In such a system, qualitative differences in motivational states would be mediated by different patterns of arousal originating in the brainstem and selectively activating different patterns of cortical activity. This system represents a compromise with Stellar's or Morgan's position in that it shifts some of the responsibility for qualitative motivational differences from diffuse cortical mechanisms onto differentiated subcortical structures. It still retains, however, the concept of the general effects of arousal, and the idea that arousal can be supported by sensory input and by cortico-reticular influences. These are the features which Stellar's theory lacks or treats summarily. They are necessary if the theory is to have the broad applicability to complex motivational phenomena, such as curiosity and problem seeking, which was provided by Hebb's drive-arousal theory.

The apparent necessity for compromise does not in itself indicate what form the compromise should take. Nor is it possible to attempt such a task here. Some progress toward the formulation of a more inclusive theory, 
however, may be made by examination of the neural mechanisms subserving motivation that are postulated in the two theories, for it is here that a point of contact between them is found.

\section{Physiologica1 Mechanisms}

In both drive-arousal and specific-center theories, changes in motivational state are brought about by changes in the average neural discharge rate, or tonic activity, of certain subcortical structures. In drive-arousal theory, increases in arousal are mediated by increases in the overall firing rate of the reticular formation, projecting diffusely to the cortex. Similarly, in Stellar's specific-centre formulation, "the amount of motivated behaviour is a direct function of the amount of activity in certain excitatory centres in the hypothalamus" $(1954, \mathrm{p} 6)$. It may be noted also that other theorists suggest mechanisms involving tonic excitatory or inhibitory effects of reticular formation (Lindsley, 1951) or 1imbic structures (Douglas and Pribram, 1966) as a neural basis of motivational and emotional variables. A similar assumption is implied whenever use is made of the idea of one nucleus, or population of ce11s exciting or inhibiting another population, with functional consequences. 
The attraction of the concept of tonic neural activity for motivational theorists derives from several sources. A motivational state, whether it is a general one like arousal, or a more specific one like hunger, appears to affect many different motor and perceptual systems, influencing the whole organisation of behaviour. Motivationa1 states also have the property of being continuous1y variable over a wide range of values. In broad terms, such pervasive, graded processes are relatively easily visualised in terms of gradually changing tonic firing rates of diffusely projecting structures.

Some Indirect physiological evidence linking tonic neural activity to motivational parameters has been provided by the success of brain lesion and electrical stimulation techniques in producing changes in motivational states. It has been noted above that dramatic alterations in mood, hunger, thirst, sexual behaviour, sleep-wakefulness cycles, and other natural behaviour patterns may be produced by stimulating or destroying specific brain sites (see reviews by Stellar (1954) and Grossman, 1967). Although the precise mechanisms mediating such effects are obscure, these techniques lend themselves to interpretation in terms of diffuse activation (or de-activation) of cell populations-- 
that is, in terms of tonic neural activity. The further assumption that changes in tonic activity in discrete areas also underlie motivational changes in naturally behaving animals has, in turn, led to such formulations as Stellar's, in which functional effects on behaviour are attributed to average cell discharge rates rather than to patterned neural activity within these areas, or to other neural parameters.

While stimulation or destruction of diencephalic centres tends to produce changes in specific motivational states, stimulation or destruction of midbrain reticular sites produces more general effects on cortical and motor excitability (see review by Lindsley, 1960). Hebb (1955) used these results to support the psychological idea of an intensity factor in behaviour which operates in at least partial independence of factors governing qualitative behavioural changes. As in Stellar's interpretation of the hypothalamic data, the proposed underlying neural mechanism is simply the overall firing rate, or tonic neural activity, of the reticular formation.

\section{Measures of Arousal}

Postulated relationships between the activity of the reticular formation and behavioural arousal are based 
mainly on extrapolation from neurophysiological studies of anesthetized or awake, immobilised preparations (referred to above), and on some work using electrical stimulation or lesionsin chronic preparations (French and Magoun, 1952; Segundo, Arana and French, 1955). Studies involving arousal in naturally behaving animals have relied on indirect measures, including autonomic variables such as heart rate or skin conductance, and on electroencephalographic (EEG) measures. Autonomic measures have been used with some success as indices of arousal or activation level (for reviews, see Malmo, 1959, 1962; Duffy, 1962) but have inherent limitations. Apart from the problem of deciding which measure to accept as the "true" indicator of arousal when measures diverge, autonomic indices give no direct information about the neural mechanisms underlying changes in behavioural arousal levels. The use of such measures is based on the assumption of some unitary central variable--arousal--which is reflected by the autonomic index selected, but provides no means of testing the assumption.

On the other hand, while EEG waves reflect more central processs they correlate poorly with behavioural arousal indices, are difficult to quantify or scale, and hard to interpret physiologically. Firstly, behavioural 
criteria suggest (and autonomic measures, to some extent, provide) a scale of arousal varying from low in sleepy or drowsy states to high in excited states. While EEG generally provides a reliable index of the change from sleep (or drowsiness) to alertness, by changing from large slow waves to small fast waves, the measure has very little discriminative ability within the waking condition. In addition, anomalous slow waves in active animals sometimes occur, as during feeding or drinking (Clemente, 1964; Roth, Steinman and Clemente, 1967) or in response to the administration of atropine (Wikler, 1952). Secondly, the relationship between EEG waves and neuronal activity is still poorly understood. While some studies have revealed relationships between cortical cell membrane potentials and surface EEG waves ( $\mathrm{Li}$, Cullen and Jasper, 1956; Purpura and Schafer, 1964; Purpura, Schafer and Musgrave, 1964; Creutzfeldt, Watanabe and Lux, 1966) the mechanisms generating EEG waves have not yet been fully explained. Furthermore, in a study of freely moving cats, Buchwald, Halas and Schram (1966a) failed to find any simple relationship between EEG waves and multi-unit activity recorded from the same electrode. Thus, although EEG measures provide our main direct link between brain 
activity on the one hand and behavioural arousal on the other, its correlation with behaviour is poor, and its relation to neuronal activity is obscure.

None of these measures really bridge the gap between behavioural measures of arousal (or other motivational parameters) and the brain mechanisms underlying them. The theories of motivation discussed above, which use the concept of tonic activity (or "amount of neural activity"), contain implicit or explicit statements about the relationship between motivation and average cell discharge rates. Insofar as they depend on data derived from stimulation techniques, such statements involve the assumptions that (a) electrical stimulation generally increases the firing rate of cell populations in the vicinity of the electrode tip, and (b) such increases in particular cell populations underlie normal function in unstimulated animals.

Few attempts have been made to examine the latter assumption by means of direct recording of cell discharge rates. One reason for this is that the recording of action potentials in freely moving animals, which can exhibit motivational changes, is technically difficult. Moreover, in order to derive average population discharge rates from recordings of single cells, successive recordings of very 
large samples of cells is required. Thus discussion of single cell data usually emphasizes parameters such as changes in the discharge rates and patterns of individual units, or differences in patterns of activity of cells within a given population, rather than average population discharge rates. However, increasing use is being made of "multi-unit" techniques to obtain more direct measures of average population firing rates in restricted areas of the brains of unanesthetized animals. In addition, measures of local metabolic changes in the brain may also reflect overa11 increases or decreases in neuronal discharge rates. Studies using these techniques will be discussed below, with emphasis on experiments involving motivational parameters in freely moving anima1s, (in most cases, cats).

\section{Measures of Tonic Activity}

The "tonic neural activity" of an area may be defined as the total number of action potentials occurring in that area in a given time. It should be noted that tonic activity is a population parameter, and the tonic activity of a given population as whole could, theoretically, be largely independent of patterned changes within that population. 
The most direct method of estimating this quantity is to use the multiple unit, or multi-unit technique. The signal from a macroelectrode (usually filtered to pass only impulses in the frequency range of action potentials) is rectified and integrated. It is usually assumed that the d-c output of the integrator provides a measure of the discharge rate of the cells around the tip of the electrode. The reasons for assuming this relationship are discussed in the appendix. The method was originally used in the study of peripheral nerve responses (Beidler, 1953; Pfaffmann, 1955) and subsequently applied to the study of cell population responses within the central nervous system (Arduini and Pinneo, 1963; Schlag and Balvin, 1963). In some of the studies discussed below (Starr and Livingston, 1963; Galen, 1965) a wider pass band is used, so that low frequency signa1s, (including conventional EEG frequencies) are included in the integration.

Attempts have a1so been made to estimate the population firing rate by examination of action potentials recorded from single neurons with microelectrodes. If a single cell study includes a sufficiently large number of units, each of which has been monitored under two or more conditions (e.g. sleep and wakefulness), the rates can be 
averaged to provide a measure of population firing rates under the two conditions. In many studies, the number of cells monitored is not large enough to provide a reliable extimate of population firing rates; individual cel1 discharge rates may vary widely, and there may also be differences in the pattern and direction of responses in neighborouring cells in the same population. Where such estimates have been made, however, the conclusions arrived at are generally consistent with the results of multi-unit studies.

The measurement of tonic activity has also been approached indirectly by recording indices of local metabolic activity in the brain, on the assumption that localised changes in metabolic rate will reflect gross changes in the mean firing rates of local neural elements. Measures of oxygen tension (Travis and Clark, 1965; Gijsbers and Melzack, 1967) and local temperature fluctuations (Hull, Buchwa1d, Dubrovsky and Garcia, 1965; Melzack and Casey, 1967; McE11igott and Melzack, 1967) have been obtained in chronic preparations. Simultaneous temperature and multiunit records from the same electrodes have shown close correlations between the two measures (McE1ligott and Me1zack, 1967; Gijsbers and Melzack, 1967). 


\section{Mu1ti-Unit Measures and Sensory Systems}

Integrated multi-unit recordings have been used mainly to study the responses of cell or fiber populations to sensory stimuli. Several aspects of this work elucidate both the fumctional significance of population discharge rates in general, as well as the effects of motivational variables on sensory processes. The technique was first used for recording chorda tympani responses to gusseatory stimulation (Beidler, 1953; Pfaffmann, 1955), and was subsequently adapted for recording activity from a variety of sensory systems and from the central nervous system, in anesthetized or awake, immobilised (Arduini and Pinneo, 1963) and freely moving (Starr and Livingston, 1963, Benoit, 1964, Weber and Buchwa1d, 1965) cat preparations. These studies have provided information about the nature of olfactory, visual and auditory processes which has not been readily available using other techniques. They have demonstrated that increases in the intensity or frequency of stimulation result typically in increased average discharge rates not on1y in nerves which innervate receptors directly, where such effects might be expected, but also in more centra1, even cortica1, 1ocations. 
Multi-unit techniques have a1so been used in awake, freely moving cats to study the effects or cell populations of prolonged or repeated stimuli. Prolonged white noise (Starr and Livingston, 1963) or repeated auditory stimuli (Galin, 1965; Buchwald, Halas and Schramm, 1966b; Podvo11 and Goodman, 1967) typica11y evoke initial increases in activity at all auditory stations (cochlear nucleus, superior olive, inferior colliculus medial geniculate nucleus and posterior ectosylvian cortex). The responses at thalamic and cortical levels are smal1 and transient, and disappear after repeated or prolonged stimulation; they are replaced in some cases by an evoked decrease in activity. In the superior olive and cochlear nucleus, the auditory responses are much larger, are sustained throughout stimulation, and are not subject to habituation during prolonged or repeated stimulation. (The susceptibility of the inferior colliculus to habituation differs in these studies). Of particular interest here are the additional findings of Buchwald et al (1966b) and Galin (1965). After habituation of the cortical and thalamic increases in multi-unit activity to auditory stimuli had occurred, foot shock was introduced following the sound. After a few trials, the auditoby 
stimulus again was able to evoke increases in the medial geniculate and posterior ectosylvian cortex. Buchwald et al. also report that the increases were now sustained throughout the stimulus period of $1.5 \mathrm{sec}$, in contrast to the transient responses obtained on initial presentation of the tone.

Compared with the lower auditory relays, the higher stations thus have smaller initial responses, which habituate rapidly and are markedly affected by motivational variables. These properties are in general accord with views of the function of these areas established on the basis of other techniques (e.g. John and Killam, 1959); what is of particular interest here is the ease with which these functional relationships are revealed by the multiunit method.

These experiments, taken together, support the idea that the tonic activity (mean discharge rate) of populations reflects the functional participation of these populations in sensory processes. Single cell studies have shown that a given cell may increase or decrease its discharge rate to a given stimulus. The multi-unit studies suggest, however, that these effects are not randomly distributed; rather participation of an 
area in response to sensory stimuli is most often accompanied by an overall increase in discharge rate. Sensory physiologists have shown increasing interest in this tonic or "background" activity.. This interest was directed initially to the extent to which such firing might influence the responses of individual neurons in a given area (e.g. Granit, 1951). More recently, however, greater stress has been given to the functional significance of tonic activity itself, both as an important experimental parameter, and as a useful conceptual tool in modelling sensory processes (Melzack and Wa11, 1965).

\section{Arousal and Tonic Activity}

The relationship between behavioural arousal and cell discharge rates in the midbrain reticular formation and other areas has been investigated using both single unit and multi-unit techniques. Benoit (1964) reported integrated multi-unit recordings from the lateral geniculate nucleus and mesencephalic reticular formation of a cat during sleep/wakefulness cycles. In both areas, levels of firing were highest when the cat was active, and gradually declined as the cat relaxed, reaching a low point in slow sleep. (Jouvet's (1967) usage of the 
terms "slow sleep" and "paradoxical sleep" is followed here.) During paradoxical sleep, both areas increased their firing rates to levels similar to those in the active waking cat.

\section{Similarly, Podvoll and Goodman (1967) recorded} integrated multi-unit discharges from many sites in the thalamus, reticular formation, caudate nucleus and colliculi in chronic cat preparations during different states of arousa1. They report changes in firing rates in thalamic and midbrain reticular areas which follow the observed behavioural arousal levels closely. The increase in neural activity from slow sleep to the highest arousal levels was of the order of $75 \%$, and the intermediate levels, classified as "quiet alert" and "drowsy" showed intermediate levels of activity in all thalamic and reticular areas studied. Neural activity in the "drowsy" state was very close to levels recorded in slow sleep. These areas also showed large increases in discharge rates during paradoxical sleep. Recordings from the amygdala, hippocampus, caudate nucleus, cochlear nucleus and colliculi showed only sma11 and inconstant changes in tonic activity during changing arousal levels and in paradoxical sleep. In both these studies the average discharge rates of cell populations 
in many areas in the thalamus and reticular formation a11 followed behavioural arousal levels closely. This suggests that these areas constitute an organised system, within which the tonic neural activity of the separate areas tend to vary together.

The literature on the activity of single neurons in freely-moving preparations generally supports the conclusions derived from multi-unit studies. Studies of single neurons in the cortex (Evarts, 1960, 1961, 1964; Evarts, Benta1, Bihari, and Hutten1ocher, 1962; Creutzfeldt and Jung, 1961; Verzeano and Negishi, 1961), lateral geniculate nucleus (Bizzi, 1966) and midbrain reticular formation (Huttenlocher, 1961; Evarts, 1961) have shown that average firing rates of cells in these areas tend to be high during strong behavioural arousal, and during paradoxical sleep; and low during slow sleep, drowsy states, and quiet wakefulness. These studies, like the multi-unit studies, have also revealed only small or insignificant differences in average discharge rates between states of quiet wakefulness and slow sleep (although significant differences in discharge rates and patterns of firing of individual units, and classes of unit, were found). 
Because "arousa1" is sometimes defined in terms of the differences between slow sleep and quiet wakefulness, these results are sometimes reported as indicating that average cell discharge rates do not vary with arousal leve1s. It should be remembered, therefore, that a wider range of behavioural arousal states is being considered here. Another factor has also led to a negative interpretation of the results of single cell studies. High average rates of discharge of reticular formation units during aroused behaviour have been interpreted by some writers (e.g. Huttenlocher, 1961) to be due merely to increased sensory input rather than reflecting the activity of specific arousal systems or mechanisms. Such a cautious interpretation may be proper when only one cell at a time is monitored, and when the cell sample is drawn exclusively from the reticular formation whose responsiveness to many sensory modes impedes experimental control of sensory factors. It is difficult, however, to explain the smooth variations in tonic activity levels in the experiments of Benoit (1964) and Podvoll and Goodman (1967) in terms of increased sensory input. Firstly, the simultaneous co-variation of activity in such areas as the lateral geniculate nucleus, medial geniculate nucleus, non-specific thalamic 
nuclei and reticular formation suggests some interna1 co-ordination of discharge rates in these areas. The "sensory" explanation would require the rather unlikely hypothesis that a11 these areas respond in the same manner to all sensory inputs. Increased sensory input must play some role in the increases in tonic activity during arousa1. Nevertheless, the co-variation of these gradual changes at reticular and thalamic sites, together with the fact that arousal-related changes are not recorded at such sites as the inferior colliculus, while sensitivity to sensory stimuli remains undiminished, (Podvoll and Goodman, 1967) suggests that the arousal-1inked changes might be attributed to some internal co-ordinating mechanism, rather than to sensory input per se. That thalamic and reticular sites can reach very high average discharge rates without any increased sensory input is evidenced by observations that tonic activity in all these areas is very high during paradoxical sleep (Benoit, 1964; Podvo11 and Goodman, 1967; Bizzi, 1966; Evarts, 1961, 1964).

Purpose of the Present Study

During pilot experiments with multi-unit recording in freely moving cats, it was observed that 
activity in the cortex and lateral geniculate nucleus was increased by any stimulus which aroused the cat, and by any spontaneous increases in behavioural activity. Decreases in the level of multi-unit activity were assoclated with decreases in behavioural alertness and activity.

Behavioural arousal thus appeared to be a major variable linked with changes in tonic neural activity. Any studies using this technique in awake, freely moving preparations, even if more specific functions were the principal target of the study, would necessarily have to take this variable into account. The investigation of this phenomenon also appeared to be important because, in spite of the fact that the concept of arousal (or activation) plays an important role in the theory of motivation, emotion and learning (Lindsley, 1961, 1960; Hebb, 1955; Ma1mo, 1959, 1962, 1964; Duffy, 1962) there is no adequate central measure of its neural correlates. Accordingly, a systematic study of the relationship between multi-unit activity and behavioural arousal levels was initiated.

The purpose of these experiments, then, was (1) to explore the range of degree of variability of tonic firing rates, as determined by the multi-unit method, in 
various parts of the brain during spontaneous changes in behavioural state, including sleep and wakefulness, and (2) to investigate the relationship between multi-unit and EEG records from these areas, since EEG activity is often used as an arousal indicator. 
METHODS

Subjects

Eleven cats, each with either 2 or 6 chronically implanted electrodes, were used in a series of recording sessions extending over a period of one week to several months (Table 1). Additional information was obtained from 5 acute preparations under sodium pentobarbital (about 40 $\mathrm{mg} / \mathrm{Kg})$ or urethane $(1.5 \mathrm{gm} / \mathrm{Kg})$ anesthesia. Surgica1 Procedure

Cats were anesthetized with $40 \mathrm{mg} / \mathrm{Kg}$ sodium pentobarbital (i.p.) and supplementary doses were given i.v. or directly into the heart to maintain moderate anesthetic levels. The cat was then placed in a Kopf stereotaxic instrument and craniotomy was performed to allow the insertion of electrodes. Coordinates were obtained from the atlas of Snider and Niemer (1961). Two or six electrodes were inserted into the brain, and, for monopolar recording, reference electrodes were placed in the frontal sinus. The ground lead was connected to a stainless steel sku1l screw. The electrodes were led to an amphenol hexagonal connector (126222), which was fixed to the skull with cranioplastic cement. The incision was sutured and antibiotics were administered. Several days were allowed for postoperative recovery before 
recording sessions started. Electrodes

Both bipolar and monopolar recording electrodes were used. Bipolar electrodes were made of two $250 \mu$-diameter strands of formvar-insulated stainless stee1 wire, twisted together, and bare at the cut ends on1y. Monopolar electrodes were made by etching $250 \mu$ stainless stee 1 wire to a conical tip, and coating with insulating compound No. 741 (National Engineering Products, Inc.) to within about $250 \mu$ of the tip, where the diameter was about $100 \mu$.

Electrodes were selected with impedences, at $1 \mathrm{KHz}$, of between 10,000 and 15,000 ohms in $0.9 \%$ saline. This range gave the best multispike recordings; the electrodes were not so sma11 that they could isolate one or two cells, which would thus dominate the integrated record, but were small enough so that some units could be identified above the background activity. Reference electrodes were of $25 q_{\mu}$ stainless steel with several millimeters of uncoated tip. Recording Equipment

During recording sessions, the cat was placed in a large $\left(5^{\prime} \times 3^{\prime} \times 3^{\prime}\right)$ enclosure with one side of glass (5'x3') to permit observation of the cat (Fig. 1). The 
enclosure contained a litter tray, a mat, and was illuminated by two 60W lamps mounted at the top of the box and shielded so that they did not throw 1ight directly into the laboratory. Signals from the cat were led from the amphenol connector with a cable made up of eight Microdot low noise cables (非250-3804) which passed through a slot in the top of the recording enclosure, and was suspended loosely by an elastic cord attached to the ceiling of the room, to permit free movement of the cat.

A block diagram of the electrical recording system is shown in Fig. 2. Signals from two electrodes were led from the cat, via selector switches, to (a) channels of a Grass mode1 7 polygraph for EEG recording, and (b) the high frequency recording equipment. The high frequency signals were first aniplified using Tektronix Differential Amplifiers (type 2A61). The pass band of the amplifiers (using the built-in filters) was set at $600 \mathrm{~Hz}$ to $6,000 \mathrm{~Hz}$ (half amplitude, $-20 \mathrm{db} /$ decade). The high pass setting at $600 \mathrm{~Hz}$ allows passage of signals in the frequency range of action potentials, but blocks EEG and other slow electrical activity; the upper cut-off, at $6,000 \mathrm{~Hz}$, reduces the possibility of contamination of the records by extraneous radio frequency signals. The amplified signals were then 
led to audio and CRT monitors, and averaged by using integrating circuits (Fig. 3) modified from Weber and Buchwald (1965). The d-c output of this circuit is proportional to the root-mean-square of a $1,000 \mathrm{~Hz}$ sine wave input. Its time constant was about $800 \mathrm{msec}$. The output of each integrator was recorded both on a d-c channe1 of the polygraph, below the EEG record for the same electrode, and on a Leeds and Northrup Speedomax $\mathrm{X}_{1}-\mathrm{X}_{2}$ two channel servo-recorder, with a chart speed of one inch per minute. The polygraph chart, running at a much higher speed, usually $6 \mathrm{~mm} / \mathrm{sec}$, revealed the more rapid multi-unit level changes, and permitted detailed comparison of these records with the EEG waves. The servorecorder, by virtue of its slower speed and wide chart (12"), provided a more convenient display of slower changes in multi-unit baseline levels.

The noise level of the system, within the pass band used, was determined by measuring the d-c output of the integrator when (a) neural activity ceased in a sacrificed cat, and (b) a 47,000 ohm resistor was substituted for the cat. The signals from different electrode placements exceeded noise levels by $2 / 1$ to $10 / 1$. Changes as small as $2 \%$ of the d-c output were discriminable even from placements (normally cortical ones) with low signal levels. The 
corresponding range of peak-to-peak input signal levels, read from the oscilloscope face, was about $20 \mu \mathrm{v}$ to $80 \mu \mathrm{v}$.

Raw (unintegrated) multi-unit signals, together with the integrated multi-unit activity and EEG signals were recorded on magnetic tape (using an Ampex SP300 recorder) in some experiments. These recordings were later transcribed onto film to permit a closer examination of the relationship between the raw and integrated multiunit records (Fig.4).

Artifact in Mu1ti-unit Records

With the recording system used here, there was virtually no problem with movement artifact as the cat moved about the enclosure. However, two conditions induced artifact in the integrated record: (a) when the cat shook its head violently, and (b) when the cat was chewing or biting vigorously(during eating or grooming) some muscle artifact entered the integrated record. The muscle potentials appeared on the visual monitor as 300-400 $\mathrm{Hz}$ waves, and were also clearly discriminable from the sound of action potentials on the audio monitor. These criteria were used to discard data which had been thus contaminated. Procedure 
to the large colony cage in which they normally lived. Before recording sessions started, each cat was introduced to the recording procedures by placing it in the testing enclosure for two hours or more per day, and received its daily meal (a bowl of comnercial cat food, and a bowl of milk) in the enclosure.

Recording sessions lasted from $1 \frac{1}{2}$ to 3 hours. The laboratory was illuminated only by reflected light from the enclosure, which provided enough working illumination for the experimenter, but made it difficult for the cat to see, or be distracted by, movements outside the enclosure. The hum of the recording equipment masked some of the background noise, but louder sounds from other parts of the laboratory were audible. A detailed commentary on the cat's behaviour throughout the session was recorded on tape and transcribed later for comparison with the electrical records.

For the larger part of the recording sessions, the cat was left undisturbed. Food and milk were placed in the enclosure either before or during the session, which provided some control over the behaviour of the cat, since it was normally alert and active before the meal, and would groom, 
rest, and often sleep afterwards.

In the course of such sessions, long samples of neural activity were obtained from each electrode. It was therefore possible to observe the neural activity in the course of extended behavioural sequences involving play and petting, walking round the enclosure, eating, drinking and sleeping, etc. Unavoidable noises in the laboratory and loud noises outside the laboratory provided many unplanned examples of responses of alerting stimuli. The cat was also alerted by intentional noises, or calling "puss puss". Another arousing stimulus was the approach of experimenter himself, as he placed food and milk bowls in the enclosure, removed the cat at the end of the session, or entered the enclosure to stroke the cat. In some instances a regular "petting sequence" was used to facilitate comparison of activity recorded under these conditions at different times. The experimenter first entered the enclosure, but did not approach the cat for 30 seconds. The cat was then stroked for one minute, and the experimenter then left. To determine whether the activity from particular electrodes was differentially sensitive to visual and auditory stimulation, tones were played, and a flashlight was waved across the cat's field of vision, or across its eyes. 
Histology

On termination of testing, each animal was deep1y anesthetized, and perfused with $0.9 \%$ saline and $10 \%$ formol saline. The brain was removed and kept in formol saline for at least a week. $40 \mu$ coronal sections were cut on a freezing microtome, and stained with Cresyl Violet alone, or Cresyl Violet and Luxo1 Fast Blue. In one instance, electrode placements were determined by copying the projected image of wet, unstained sections directly onto photographic paper. S1ides illustrating anterior thalamic, ventral tegmental and reticular placements are shown in Fig. 22. 


\section{RESULTS}

For all structures studied, a record was obtained of the continuous ongoing discharge of cells around the tip of the electrode. This tonic activity continued throughout all behavioural states in all the structures that were observed. In unanesthetized animals, the lowest average neural discharge rates recorded from a given electrode never fell below $50 \%$ of the highest rate for that placement. In one group of electrode placements, large, 1ong-term changes in tonic activity were correlated with changes in observed behavioural arousal levels. In the other areas, specific sensory input played a more important role in the control of average discharge rates.

The activity levels recorded from each implanted electrode under the same behavioural conditions were found to be very stable (within 10\%) from day to day and from week to week. The peak-to-peak amplitude of the raw, unintegrated multi-unit activity varied from $20 \mu \mathrm{v}$ to $80 \mu v$ in different placements. It is assumed that the differences are due to differences in cell size, cell density and cell discharge rates in the vicinity of the electrode, and may also have been due partly to variations 
in electrode tip area. Because of these differences at each recording site, relative changes provide a more meaningful measure than absolute voltage magnitudes. The scale on the figures illustrating integrated multi-unit records is, therefore, given as a percentage of the total signal at the lowest level recorded from a given electrode (in the unanesthetized anima1). A11 records shown in the Figures, with the exception of Fig. 7, were obtained from monopolar electrodes. The appearance of the raw multi-unit data, along with its integrated derivative and EEG activity is shown in Fig. 4.

\section{$\underline{\text { Relationships Between Multi-Unit and EEG Recordings }}$}

The electroencephalogram (EEG), in the frequency range of $1-75 \mathrm{~Hz}$, was recorded for the major part of all testing sessions. Since EEG rhythms have been widely used as an arousal measure, particular attention was paid to the relationship between EEG and multi-unit levels at the same recording site. Simultaneous EEG and multi-unit records were examined to determine the extent to which some dimension of EEG activity (amp1itude or frequency) might be accompanied regularly by changes in cell discharge rates. Four conditions in which some positive relationship or clear dissociation was found are:

1. Bursting. During high amplitude slow cortical 
EEG waves, the multi-unit activity from the same electrode tended to show a "bursting" pattern in synchrony with the EEG waves. This bursting pattern was audible on the audio monitor, and sometimes also showed up as small fluctuations in the integrated record (Fig. 5, and Fig. 11, upper trace). 2. Post reinforcement synchrony. During eating, drinking or grooming, cortical and reticular EEG records show high amplitude slow $(4-8 \mathrm{~Hz})$ waves, which are otherwise considered characteristic of a drowsy anima1. This phenomenon was noted regularly, especially during drinking, when the large slow waves would sometimes persist for a minute at a time. During such periods, the integrated multi-unit activity, though not at a particularly low leve1, was extremely steady. The characteristic appearance of the cortical and reticular records under these conditions is shown in Figs. 6 and 9a.

3. Anesthesia. EEG and multi-unit activity levels are differentially affected by barbiturate anesthesia. Sub-anesthetic doses of sodium pentobarbital, too small to reduce the amplitude of EEG activity, cause a marked diminution of multi-unit activity in reticular formation and cortex. When the anesthetic dose is increased the rate 
of cell discharge falls well below the lowest level seen in the unanesthetized animal, even before the cat is clinically anesthetized (Fig. 7). When lethal doses of pentobarbital are administered to sacrifice the cat, the multi-unit may cease almost entirely before the death of the cat, while high amplitude EEG waves may still be recorded.

4. EEG synchrony and desynchrony. The "desynchronization" of the EEG, which occurs in many areas of the brain when a drowsy cat is suddenly alerted, was often accompanied by an increase in tonic activity at the same electrode. Fig. 8 shows such an effect in the midbrain and positive reticular formation, thalamus, and ventral tegmentum. These effects were also recorded from cortical electrodes. In some cases, the increases in tonic activity may precede the EEG flattening by as much as a second (Fig. 8a). Conversely, the sudden interruption of high frequency EEG activity by slow waves would often be accompanied by a decrease in cell discharge rates (Figs 5, 11). More of 2 , however, these relationships between EEG and multi-unit recordings were ambiguous or absent (Fig. 9). The relationship between EEG and multi- 
unit activity during sleep is discussed below.

Tonic Activity and Behavioural Arousal

Multi-unit activity leve1s recorded from cortica1, reticular, midline thalamic, and ventral tegmental placements tended to vary together. Because variations in their activity levels were closely correlated with behavioural arousal levels in the waking cat, they will be referred to below as "arousal-related areas." The relationship between activity levels in sensory areas, (the latera1 geniculate and inferior colliculus) and behavioural arousal will be discussed separately.

Arousa1-related areas. The baseline levels of tonic activity in the arousal-related areas were lowest during slow sleep. The levels in a cat sitting quietly awake were 5-10\% above the slow sleep baseline. During moderate states of arousal, when the cat was walking around the enclosure, eating or drinking, activity levels were $10-20 \%$ above the slow sleep baseline. In highly aroused states (such as those evoked by the approach of the experimenter) the activity in these areas rose by 20-50\%. In paradoxical sleep, which will be discussed below in more detail, multi-unit activity in these areas 
approached very high levels seen otherwise only when the cat was high1y aroused. These relative levels were characteristic of al1 arousal-related areas, and no exceptions to this general rule were observed.

In a cat which is relaxing, and follows a behavioural sequence from a highly active state, through sitting, crouching, lying down with head up, and finally curling up to sleep, the tonic activity of arousal-related areas decreases gradually within these behavioural categories. The typical tonic activity levels quoted above for given behavioural categories can therefore only be approximate, and there is considerable overlap from one stage to another. These gradual declines in tonic activity, which take place while the avert behaviour of the cat changes very little, are illustrated in Figs. 10, 12 and 13. In Figs. 10 and 13 the cat was lying down throughout the portions of record illustrated. In Fig. 10, the baseline activity levels in both the cortex and anterior medial thalamus declined rapid1y at first, and then more slowly, with interruptions, during the ten minutes following the disturbance caused by the experimenter. In Fig. 13 (lower trace) the rapid decline in activity of the reticular formation was accompanied by a similar rapid transition from a behaviourally active phase 
(including eating and walking round the enclosure) to quiet resting and eventually, slow sleep. A similar decline in the tonic activity of the reticular formation during the transition from an active to a quiet relaxed phase of activity is seen in Fig. 12 (lower trace, between 4 min. and 7 min.).

Simultaneous recordings from different pairs of electrodes showed that the time course and relative size of these slow baseline level changes was similar in a11 arousa1-related areas. Such changes always occurred after the cat had been active or attentive to external stimuli. Thus although the slow shifts often occurred during periods when no obvious or overt behavioural changes were observed they nevertheless appeared to be related to the state of arousal of the cat, in the context of the behavioural sequences described above. Increases in the tonic activity of the arousalrelated areas were usually more abrupt than the decreases described above. They generally corresponded to the more sudden increases in behavioural alertness or activity, which occurred spontaneously, or in response to external stimuli. It was observed that the increases in tonic activity which followed external stimulation were correlated 
with the response of the cat to the stimuli, and with the novelty or "significance" of the stimuli rather than the nature of the stimuli as such. Responses in arousal-related areas to a variety of stimuli, as well as changes in tonic activity associated with spontaneous behaviour are shown in Figs. 6, 8, 10, and 13 to 17 .

The similarity between arousal responses in the cortex, midbrain and pontine reticular formation, and anterior medial thalamus is illustrated by the responses to the presence of the experimenter, and to stroking, shown in Fig. 15. It is clear that the three largest increases in tonic activity, in all areas, occurred in response to the entrance and exit of the experimenter, and to the onset of the stroking. Sensory input, or motor activity per se, were not the significant variables affecting tonic activity leve1s.

Although all the arousal-related areas showed similar baseline level changes under similar behavioural conditions, the patterns of more rapid activity changes recorded simultaneously in two arousal-related areas were never identical. The degree of detailed similarity varied with the pair of electrodes selected. Simultaneous recordings from two cortical electrodes showed the least 
difference, even though the electrodes were widely spaced (Fig. 16). Much greater differences were seen between cortical and anterior medial thalamic multi-unit records (Figs. 9b, 10 and 11) and between reticular formation and ventra1 tegmentum placements (Fig. 17). Such differences were most readily seen during the relatively quiet phases of behavioura1 (and tonic) activity, often in response to low level stimuli, or to stimuli to which the cat had habituated. These stimuli were below the threshold for producing either behavioural arousal or large generai increases in tonic activity (Figs. 9a, 10, 11).

Tonic activity in sensory nuclei. The lateral geniculate nucleus and inferior colliculus differed from arousa1-related areas. The selective effects of visual and auditory stimuli on their neural activity were easily demonstrated (Fig. 19), and tonic activity in these areas was found to be less dependent on behavioural arousal levels. Baseline activity levels in these sensory areas did not change from quiet waking to slow sleep (Figs. 20, 12). Although these areas tended to show increased activity during more aroused behaviour, the pattern of activity was quite different from that in the arousal-related areas (Figs. 12, 13). Increased neural activity in the inferior 
colliculus during active behavioural phases appeared, in most cases, to be evoked directly by the increased auditory input resulting from sounds made by the cat itself (Fig. 12). Tonic activity is not maintained at high baseline levels throughout high1y aroused behaviour, as is the case in the arousal related areas, buy may return to the slow sleep baseline during such behaviour. The largest increases in activity are clear1y correlated with auditory input. Furthermore, if the ears are covered, activity immediately drops far below the slow sleep baseline (Fig. 12).

It seems likely that increased activity in the lateral geniculate nucleus during aroused behaviour may be similarly due in large measure to the varied visual input resulting from increased body, head and eye movements. The pattern of activity changes in aroused behaviour is different from that in the arousal-related areas. When the cat is relatively inactive, and especially when the eyes are closed, the lateral geniculate does not show the slow declines in activity during relaxation, or the rapid increases in activity accompanying postural adjustments and mildly arousing stimuli seen in the arousal linked areas (Fig. 13).

Specific sensory input thus appears to be a major 
factor influencing the tonic activity levels in the lateral geniculate nucleus and inferior colliculus in the relatively free behavioural situation used in this study. At the same time, of course, not all the variations in tonic activity in these areas were attributable to specific sensory inputs. The bursts of activity in the lateral geniculate during quiet resting behaviour (with eyes closed) and in slow sleep (Figs. 13, 20), and the small variations in baseline level of the inferior colliculus during the same behavioural conditions (Figs. 12, 20) both appeared to be independent of stimulus changes, as did the activity of these areas during paradoxical sleep (see below).

It may be noted also that the general appearance of the integrated multi-unit record of the lateral geniculate and inferior colliculus differs from that of the arousa1related areas. The lateral geniculate in particular, during quiet resting or slow sleep, tends to show long periods (up to a minute) of extremely stable baseline, interrupted by bursts of activity lasting a few seconds (Figs. 13, 19, 20), an observation never made in the arousa1-re1ated areas.

\section{Sleep}

The variations of the arousal-related areas are 
as high1y associated during sleep as they are in the waking state. Neural activity is at the lowest level during slow sleep; variability of activity is also very low (Figs. 21,12) at this time. During paradoxical sleep, cell discharge rates rise to very high levels, and intermittent bursts of intense activity occur (Fig. 21). The paradoxical phase of sleep lasts about 5 to 8 minutes, and during prolonged periods of sleep recurs at intervals of about 20 minutes. The increase in tonic activity which marks the onset of paradoxical sleep is not always as abrupt as that shown in Fig. 21, and may begin many seconds before the decrease in amplitude of EEG which usually defines this phase of sleep. Multi-unit records also reveal a structure within paradoxical sleep which is not evident from the EEG record. The increase in tonic activity, from the initial slow sleep level to the high baseline level seen in the middle portion of paradoxical sleep, takes place slowly over two or three minutes. The decline at the end of the phase is similarly gradual. On the falling phase, just before re-entering the slow sleep, the cat of ten awoke briefly, and this behaviour was accompanied by an increase in tonic activity. The brief bursts of intense activity which are observed during paradoxical sleep (Fig. 21) tend to occur simultaneously 
in arousal-related areas. They occur very irregularly throughout paradoxical sleep, during the rising, steady and falling phases. This general description holds for a11 arousal-related areas except the ventral tegmentum from which paradoxical sleep records were not obtained.

As mentioned above, baseline levels do not decline in the lateral geniculate nucleus and inferior colliculus during the transition from quiet waking (with eyes closed) to slow sleep. Nor does the amplitude of more rapid variation decrease, as it does in the arousal-related areas (Fig. 20).

Both areas, however, show characteristic patterns of activity during paradoxical sleep. In the lateral geniculate, the irregular bursts of activity which occur in slow sleep become more frequent, and increase in amplitude. These bursts of activity are much more frequent than those that occur in the arousal related areas during paradoxical sleep. Although the baseline activity level of the lateral geniculate is elevated during paradoxical sleep, as in the arousa1-related areas, it differs from these areas in that quiescent periods, during which the activity drops to the slow sleep baseline, sometimes occur within the paradoxical phase. 
The inferior colliculus baseline level does not increase during paradoxical sleep (Figs. 20, 12). There is a considerable increase in the variability of the record however, which frequently takes the form of large decreases in activity, a phenomenon not obtained in any other recording site. There was also some evidence of a reciprocal relationship with the lateral geniculate, in that these decreases in the activity of the inferior colliculus tended to occur simultaneously with the largest increases in 1ateral geniculate activity (Fig. 20). 


\section{DISCUSSION}

The observation that tonic activity of cell populations in widespread areas of the brain tend to vary together confirms and extends the earlier findings by Benoit (1964) and Podvoll and Goodman (1967). These areas, which have been shown in this study to include portions of the cortex, thalamus and reticular formation, show average rates of cell discharge that are highly correlated with one another, and with the observed behavioural arousal level of the animal. Increases in tonic activity in these areas accompany spontaneous or stimulus-evoked behavioural arousa1, while decreases in activity occur during periods of relaxation. The high degree of inter-correlation of activity among the areas led to their designation as "arousa1-related areas". Although these areas appear to share a common function, they do not necessarily subserve only this function. There are also marked differences in the pattern of changes which are presumably related to the more specialised functional roles played by each of the different areas.

In contrast with the activity observed in the arousa1-related areas, the tonic activity levels in the 
two sensory areas that were studied were more dependent on specific sensory input. Increases in activity in the lateral geniculate nucleus and the inferior colliculus were produced by visual and auditory stimuli, respectively, indicating their more specific functions in the processing of sensory information. It is clear, however, that factors other than sensory input must be responsible for variations in the activity of these areas during sleep. Inputs from other cerebra1 areas, in a11 probability, also contribute to the patterns of activity in the two areas during aroused behaviour.

The relationships between neuronal discharge rates and EEG waves in this study are, in general, consistent with those found in recent investigations. The observation that desynchronisation of EEG waves was sometimes accompanied by, or preceded by increases in tonic activity recorded from the same electrode confirms similar observations by Schlag and Balvin (1963), who found a very high correlation between increases in cortical and reticular tonic activity and EEG desychronization at the same electrode site. Such observations were common in this study, at thalamic and ventral tegmental recording sites, as well as at the cortex and 
reticular formation. More often, however, EEG and tonic activity changes were not related in any obvious way, and appeared to be independent. Marked increases in tonic activity were observed while the EEG appeared unchanged and, conversely, EEG changes occurred without any marked change in the multi-unit record. This finding is in accord with the study by Buchwald et al (1966b), who found no consistent relationship between multi-unit and EEG measures.

On the basis of studies (Li, Cullen and Jasper, 1956; Purpura and Schafer, 1964; Creutzfe1dt, Watanabe and Lux, 1966) which show a close relationship between surface cortical EEG waves and cellular membrane potentials, one might expect to find close relationships between EEG waves and the probability of cell discharge (and hence the average firing rate for a whole population). However, the relationship between surface EEG waves and unit membrane potentials is by no means simple (e.g. Morre11, 1967). The absence of any well defined relationships in this study (and in that by Buchwald et al., 1966b) suggest that if any constant correlation does exist between population discharge rates and local EEG waves, it is a very subtle one. Although it is obvious that changes 
in EEG patterns, and the marked changes in unit firing patterns which sometimes accompany them, must play an important role in brain function, it is difficult to relate these measures in any simple way either to population discharge rates, or to behavioural arousal. In view, therefore, of the close relationship observed between average cell discharge rates and observed behavioural arousal levels, it is suggested that the measurement of tonic activity provides a more reliable and discriminating index of behavioural arousal levels than that provided by the EEG. In addition, such a measure may well provide more insight into the nature of the neura1 mechanisms subserving arousa1.

The idea that increases in cell discharge rates in all or part of the brain constitute the neural substrate of behavioural arousal is, of course, not new. In the first place, it derives from the simple idea that when an animal is more actively involved in its environment its neurons have to fire more, and when the animal rests or sleeps, the neurons have no work to do and can stop firing. The discovery that the brain, and even receptors, are continuously active during sleep as we 11 as waking made any simple form of this idea impossible 
to support. Nevertheless, some support for a modified version of the idea was provided by studies of the effects of electrical stimulation and lesions in the reticular formation initiated by Moruzzi and Magoun (1949). On the basis of this work, together with behavioural considerations, Hebb (1955) suggested that increased reticular-cortical firing would, by increasing the firing rate of cortical cells, bring them into a condition of optimal organisation. He proposed, moreover, that further increases in cortical activity beyond this point would lead to disorganisation of cortical activity, and disorganised behaviour.

Further doubt, however, was cast on even this modified version of a tonic neural substrate for behavioural arousa1 when techniques were developed for monitoring single cells in freely moving animals. In both cortex (Evarts, 1960, 1961, 1964; Creutzfeldt and Jung, 1961; Verzeano and Negishi 1961; Evarts et a1, 1962) and reticular formation, (Evarts, 1961; Hutlenlocher, 1961) single cell studies revealed very significant changes in the pattern of firing of cells, but only small or insignificant changes in the average firing rates when the animal awoke or went to sleep. These findings 
suggested that it might be more profitable to think of reticulo-cortical interactions in terms of patterns of unit activity, rather than the "tonic" effect of average discharge rates. The results of this study, and those of Benoit (1964) and Podvoll and Goodman (1967), indicate that this interpretation of the single cell studies is inadequate; this is partly because of the problems involved in determining average discharge rates from unit data, and partly because, rather surprisingly, the changes in tonic activity which occur when the animal goes to sleep are very small. The results of the present study support the finding (in single cell studies) that the differences in average firing rates in the cortex and reticular formation between states of sleep and quiet wakefulness are sma11. However, it was also demonstrated that over the rest of the arousal continuum, from quiet resting to excitement, tonic firing rates do change, by as much as $50 \%$ of the resting activity leve1.

These large changes during arousal are consistent with the original views that the overall activity of the reticular formation increases during arousal--a conception which was based on the effects of lesions or electrical stimulation of the reticular formation. The results of 
the present study confirm that such changes take place in the normal animal. In addition, the fact that similar changes were observed simultaneously in the cortex lends some support to models in which tonic activity is suggested as a basis for arousal-1inked changes in cortical organisation, or for the mechanisms of cortico-reticular interactions.

Parts of the thalamus and ventral tegmentum also took part in arousal reactions, in a manner similar to cortical and reticular areas. The evidence in this study, taken alone, implicates a11 these areas equa11y, and no evidence was seen to indicate that any area played a dominant role, or preceded other areas consistently in their responses to arousing stimuli. Intervals of less than $200 \mathrm{msec}$ (at best) were not discriminable with the recording system used, however, and the above finding does not imply that the activity of the rest of the system was not, in fact, preceded by, and to some extent controlled by, reticular formation activity, as other studies have suggested.

In addition to the overall correlated variations in tonic activity in the arousal-related areas, marked differences, of various degrees, were seen in different 
areas. Although no specific investigation was made of these differences, it is assumed that they were related to functional differences between the areas. These differences may be considered in the light of other evidence relating tonic activity to specific motivational functions.

Stellar (1954) has proposed that particular motivational states are dependent on the tonic neural activity in specific neural centres. It was pointed out in the introduction that attempts to extend such a view into a general theory of motivation meets difficulties in dealing with interactions between different motivational systems, and with more complex aspects of mammalian motivation. It is suggested that such difficulties encountered by Stellar (1954) or by Morgan (1943, 1957) as we11 as some of the problems that drive-arousal theory (Hebb, 1955) has in dealing with motivational specificity, may be avoided if the "specific motivational centres" of Stellar are considered not as separate from, but as part of one genera1 arousa1 system. Within this system (comprising, perhaps, parts of, or all of, the cortex, reticular formation, thalamus and hypothalamus) positive and negative feedback would, for a given state of behavioural 
arousa1, maintain the activity levels throughout the system within given limits. Within these 1imits, relative variations in levels of activity in different areas would mediate qualitative differences in motivational states.

One may consider, for example, the pattern of activity that would be expected, on the basis of this hypothesis, in Stellar's excitatory and inhibitory centres for eating, which will be assumed to be the latera1 and ventromedial hypothalamus, respectively. In the satiated condition, the ventromedial area will be more active than the lateral hypothalamus. During arousal responses not specifically involving hunger motivation, the activity of both areas would increase equally, so that the relative activity of the two areas remains the same, as does the relative activity of these areas and other arousal-related areas. In an arousing situation in which hunger motivation is involved, however, the activity of the lateral hypothalamus will increase relative to the ventromedial hypothalamus, and relative to the other arousa1-related areas (regardless of the absolute size of the increase associated with the arousal in al1 arousa1-related areas). This relative 
change will bias the whole system towards food-related responses.

This schema can not on 1 y accomodate both general and specific aspects of motivation, but also provides at least an elementary approach to the relationship between them. The limitations of this approach are numerous, and will not be discussed here; a major virtue of the hypothesis, however, is that it is immediately accessible to further experimentation, using the multi-unit recording method.

Schlag and Balvin (1963) noted that changes in cortical multi-unit activity, while indicating that "something was going on" in the area, did not indicate what was going on, and they could not assume that an increase in cell discharge rate necessarily indicated an increases in the "functional performances" of the area. The evidence reviewed above has, on the whole, indicated that increases in motivational functions are most often accompanied by increases in the tonic activity of the areas subserving those functions, In sensory systems, a1so, it would appear that in general increased sensory input, or increased variations in sensory input lead to increases in neural activity in the appropriate 
sensory areas. This effect has been demonstrated for the visua1 (Arduini and Pinneo, 1963; McE11igott and Me1zack, 1967) auditory (Starr and Livingston, 1963; and Ga1in, 1965; Buchwa1d et a1, 1966a) somatosensory (Melzack and Casey, 1967) and gustatory (Beidler, 1963, Pfaffman, 1955) systems. Insofar as it is possible to make statements about the functional correlates of changes in tonic activity levels, it thus appears that in most cases, whether sensory or motivational factors are being considered, increases in function are accompanied by increases in tonic activity. There are exceptions to this general rule, and how far it can be carried remains to be seen; however, it may well be a profitable idea to consider in modelling brain processes.

The suggestion that the functional state of a neuron population is reflected in its level of tonic activity, and that the tonic output of a given population contains significant information does not imply that information in the same population may not also be coded and transmitted in other forms. The tonic activity model is theoretically quite compatible with models of neural function based on studies of patterns of single cell activity. The fact that patterned changes can be independent 
of tonic activity changes is most dramatically illustrated by the widespread changes in cortex and reticular formation from "random" to grouped discharges which occur when an animal relaxes or goes to sleep. In spite of this general and spectacular change in patterns of unit activity, tonic rates change very little.

The kind of information transmission mode1 which is suggested by such studies as those of Hube1 and Wiese1 (1959) is also compatible with the tonic activity model. It is quite possible, for instance, to consider ce11s which are involved in transmitting highly specific information on a cel1-to-cel1 basis also being simultaneous1y involved in overall tonic changes. The average firing rate of the cells could easily change by 10 or $20 \%$ without necessarily disturbing the transmission of specific patterned information through the same population (Fig.23). The tonic input and output, and the specific patterned input and output of a population may thus be regarded as potentially independent information channels; in addition, however, it is also possible for interactions between the two systems to take place. 


\section{SUMMARY}

The multi-unit recording technique was used to study the activity of neuron populations in various brain locations in cats during 1ong, natural behaviour sequences in a free behavioural situation. Electroencephalographic (EEG) records were also obtained from each recording site. The total multi-unit activity levels in many of these areas, including parts of the cortex, thalamus and reticular formation, tended to co-vary, and these variations in tonic activity were associated with the observed behavioural arousal level of the cat. Variations in tonic activity in other areas (1atera1 geniculate nucleus and inferior colliculus) were shown to be more reliably correlated with specific sensory input than with arousal leve1s. Behavioural arousal levels appear to be more closely related to tonic neural activity in many areas of the brain than to the EEG record. The neural bases of specific-center and drive-arousal theories of motivation are examined in the light of these data. 


\section{REFERENCES}

Andersson, B., and Wyrwicka, W. The elicitation of a drinking motor conditioned reaction by electrical stimulation of the hypothalamic "drinking area" in the goat. Acta. physiol. Scand., 1957, 41, 194-198. Arduini, A., and Pinneo, L.R. The effects of flicker and steady illumination on the activity of the cat visual system. Arch. 1ta1. Bio1., 1963, 101, 508-529.

Beidler, L.M. Properties of chemoreceptors of tongue of rat. J. Neurophysio1., 1953, 16, 595-607.

Benoit, 0. Activité unitaire du nerf optique, du-corps genouillé latéral et de 1a formation réticulaire durant les differents stades de sommeil. J. Physiol. Paris, 1964, 56, 259-262.

Bizzi, E. Discharge patterns of single geniculate neurons during rapid eye movement sleep. J. Neurophysiol., $1966, \underline{29}, 1087-1095$.

Buchwald, J.S., Halas, E.S., and Schramm, S. (a) Changes in cortical and subcortical unit activity during behavioura1 conditioning. Physiol. Behav., 1966, 1, 11-22. 
Buchwald, J.S., Halas, E.S., and Schramm, S. (b) Relationships of neuronal spike populations and EEG activity in chronic cats. Electroenceph. c1in. Neurophysiol., $1966, \underline{21}, 227-238$.

Butler, R.A. Discrimination learning by rhesus monkeys to visual-exploration motivation. J. comp. physiol. Psychol., 1953, 46, 95-98.

Butler, R.A. and Harlow, H.F. Persistence of visual exploration in monkeys. J. comp. physiol. Psychol., 1954, 47, 257-263.

Clemente, C.D., Sterman, M.B., and Wyrwicka, W. Postreinforcement EEG synchronization during alimentary behaviour. Electroenceph. c1in. Neurophysiol., 1964, $16,355-365$.

Coons, E.E., Levak, M., and Miller, N.E. Lateral hypothalamus: learning of food-seeking response motivated by electrical stimulation. Science, 1965, 150, 13201321.

Creutzfe1dt, O.D., and Jung, R. Neuronal discharge in the cat's motor cortex during sleep and arousal. In Wolstenholme, G.E.W. and $O^{\prime}$ Connor, M. The nature of sleep, London: Churchi11, 1961. 
Creutzfeldt, O.D., Watanabe, S., and Lux, H.D. Relations between EEG phenomena and potentials of single cortical cells. II Spontaneous and convulsoid activity. Electroenceph. clin. Neurophysiol., 1966, 20, $19-37$.

Duffy, E. Activation and behaviour. New York: Wiley, 1962. Evarts, E.V. Spontaneous and evoked activity in single units in visual cortex of cat during sleeping and waking. Fed. Proc., 1960, 19, 290.

Evarts, E.V. Effects of sleep and waking on activity of single units in the unrestrained cat. In Wolstenholma, G.E.W., and O'Connor, M., (Eds.), The nature of sleep. London: Churchi11, 1961.

Evarts, E.V. Temporal patterns of discharge of pyramidal tract neurons during sleep and waking in the monkey. J. Neurophysio1., 1964, 27, 152-172.

Evarts, E.V., Benta1, E., Bihari, B., and Huttenlocher, P.R. Spontaneous discharge of single neurons during sleep and waking. Science, 1962, 135, 726-728.

French, J.D., and Magoun, H.W. Effects of chronic lesions in central cephalic brainstem of monkeys. A.M.A. Arch. Neuro1. Psychiat., 1952, 68, 591-604. 
Galin, D. Background and evoked activity in the auditory pathway. Effects of noise-shock pairings. Science, $1965,149,761-763$.

Gijsbers, K., and Melzack, R. Oxygen tension changes evoked in the brain by visual stimulation. Science, $1967,156,1392-1393$.

Granit, R. Receptors and sensory perception. New Haven: Yale University Press, 1955.

Grossman, S.P. A textbook of physiological psychology. New York: Wiley, 1967.

Havelka, J. Problem-seeking behaviour in rats. Canad. J. Psychol. 1956, 10, 91-97.

Hebb, D.O. On the nature of fear. Psychol. Rev., 1953, 53, 259-276.

Hebb, D.0. Drives and the c.n.s. (conceptual nervous system). Psychol. Rev., 1955, 62, 243-254.

Hebb, D.0. A textbook of psychology. Philadelphia: Saunders, 1958.

Hess, W.R. The functional organization of the diencephalon. New York: Grune and Stratton, 1957.

Hinde, R.A. Animal behaviour. New York: McGraw Hill, 1966. Hube1, D.H. and Wiese1, T.N. Receptive fields of single neurones in the cat's striate cortex. J. Physiol. (London), 1959, 148, 574-591. 
Hul1, C.D., Buchwald, N.A., Dubrovsky, B., and Garcia, J. Brain temperature and arousa1. Exper. Neuro1., 1965, 12, 238-246.

Hul1, C.L. Principles of behaviour. N.Y. AppletonCentury 1943.

Huttenlocher, P.R. Evoked and spontaneous activity in single units of medial brain stem during natural sleep and waking. J. Neurophysiol., 1961, 24, 451-468.

John, E.R., and Killam, K.F. Electrophysiological correlates of avoidance conditioning in the cat. J. Pharmaco1., 1959, 125, 252-274.

Jouvet, M. Neurophysiology of the states of sleep. Physio1. Rev., 1967, 47, 117-177.

Kohler, W. The mentality of apes. New York: Harcourt, Brace, 1925.

Li, C.-L., Cullen, C., and Jasper, H.H. Laminar microelectrode analysis of cortical unspecific recruiting responses and spontaneous rhythms. J. Neurophysio1., 1956, 19, 131-143.

Lindsley, D.B. Emotion. In Handbook of experimenta1 psychology. S.S. Stevens, Ed. New York: Wiley, 1951. 
Lindsley, D.B. Attention, consciousness, sleep and wakefulness. In Handbook of physiology, sect I, vol. III. J. Field, H.W. Magoun, and V.E. Ha1l, Eds. Washington: Amer. Physiol. Soc., 1960.

Malmo, R.B. Activation, a neuropsychological dimension. Psycho1. Rev., 1959, 66, 367-386.

Malmo, R.B. Activation. In Experimental foundations of clinical psychology. A.J. Bachrach, Ed. Basic Books Publishing Co., Inc., 1962.

McDouga11, W. Outline of psychology. New York: Scribner 1923.

McE11igott, J.G., and Melzack, R. Localized therma1 changes evoked in the brain by visual and auditory stimulation. Exper. Neuro1., 1967, 17, 293-312. Melzack, R. Irrational fears in the dog. Canad. J. Psycho1., 1952, ․, 141-147.

Melzack, R., and Casey, K.L. Localized temperature changes evoked in the brain by somatic stimulation. Exper. Neuro1., 1967, 17, 276-292.

Melzack, R., and Wa11, P.D. Pain mechanisms: a new theory. Science, 1965, 150, 971-979. 
Mendelson, J., and Chorover, S.L. Lateral hypothalamic stimulation in satiated rats: T-maze learning for food. Science, $1965, \underline{149}, 559-561$.

Morgan, C.T. Physiological psychology. New York: McGrawHi11, 1943.

Morgan, C.T. Physiological mechanisms of motivation. In Nebraska symposium on motivation. M.R. Jones, Ed. Lincoln: University of Nebraska Press, 1957. Morre11, F. Electrical signs of sensory coding. In The Neurosciences, G.C.Quarton, T. Melnechuk and F.0. Schmitt, Eds. New York: Rockefeller Univ. Press, 1967. Moruzzi, G. and H.W. Magoun. Brain stem reticular formation and activation of the EEG. Electroenceph. c1in. Neurophysio1., 1949, 1, 455-473.

Pfaffmann, C. Gustatory nerve impulses in rat, cat and rabbit. J. Neurophysiol., 1955, 18, 429-440. Podvo11, E.M., and Goodman, S.J. Averaged neura1 electrical activity and arousa1. Science, 1967, 155, 223-225. Purpura, D.P., and Schafer, R.J. Cortical intracellular potentials during augmenting and recruiting responses. I. Effects of injected hyperpolarizing currents on evoked membrane potential changes. J. Neurophysiol., $1964,27,117-132$. 
Purpura, D.P., Schafer, R.J., and Musgrave, F.S.

Cortical intracellular potentials during augmenting and recruiting responses. II. Patterns of synaptic activities in pyramidal and nonpyramidal tract neurons. J. Neurophysio1., 1964, $\underline{27}, 133-151$.

Roth, S.R., Sterman, M.B., and Clemente, C.D. Comparison of EEG correlates of reinforcement, internal inhibition and sleep. Electroenceph. clin. Neurophysiol., 1967, 23, 509-520.

Schlag, J. and Balvin, R. Background activity in the cerebral cortex and reticular formation in relation with the electroencephalogram. Exper. Neurol., 1963, $\underline{8}, 203-219$.

Schreiner, L.H., Lindsley, D.B., and Magoun, H.W. Role of brainstem facilitatory systems in maintenance of spasticity. J. Neurophysio1., 1949, 12, 207-216.

Segundo, J.P., Arana, R., and French, J.D. Behavioural arousal by stimulation of the brain in the monkey. J. Neurosurg., 1955, 12, 601-613.

Snider, R.S., and Niemer, W.T. A stereotaxic atlas of the cat brain. Chicago: University of Chicago Press, 1961. 
Starr, A., and Livingston, R.B. Long-lasting nervous system responses to prolonged sound stimulation in waking cats. J. Neurophysiol. 1963, 26, 417-431. Stellar, E. The physiology of motivation. Psych. Rev., $1954, \underline{61}, 5-22$.

Travis, R.P., and Clark, L.C. Changes in evoked brain oxygen during sensory stimulation and conditioning. Electroenceph. clin. Neurophysio1., 1965, 19, 484491.

Verzeono, M., and Negishi, K. Neuronal activity in wakefulness and sleep. In Wolstenholme, G.E.W., and $\mathrm{O}^{\prime}$ Connor, M. (Eds.) The nature of sleep. London: Churchi11, 1961.

Weber, D., and Buchwald, J.S. A technique for recording and integrating multiple-unit activity simultaneously with the EEG in chronic anima1s. Electroenceph. c1in. Neurophysio1., 1965, 19, 190-192.

Wikler, A. Pharmacologic dissociation of behaviour and EEG "sleep patterns" in dogs. Proc. Soc. exp. Blol. Med., 1952, 7.9, 261-265.

Woodworth, R.S., and Schlosberg, H. Experimental psychology. New York, Henry Holt and Co., 1954. 
Table 1. Showing distribution of electrode placements and recording periods for each cat. 


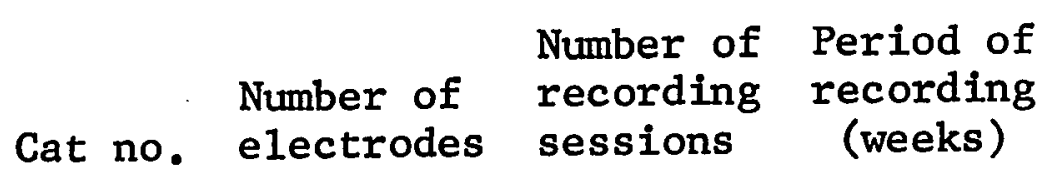

$$
\text { Location of electrodes }
$$

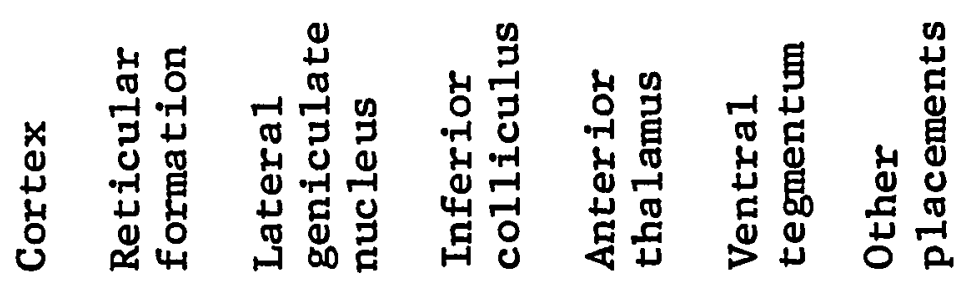

$\begin{array}{rrrrrrrrrr}1 & 1 & 1 & 1 & 1 & & & & \\ 2 & 1 & 2 & 1 & 1 & & & & \\ 3 & 2 & 15 & 4 & 1 & & & & \\ 4 & 2 & 4 & 1 & & & 1 & & \\ 5 & 2 & 15 & 4 & 1 & & & & & \\ 6 & 2 & 15 & 3 & 1 & & & & & \\ 7 & 2 & 4 & 2 & 1 & 1 & & & & \\ 8 & 6 & 10 & 13 & 2 & 2 & 1 & & & \\ 9 & 6 & 3 & 2 & 1 & 1 & 1 & 1 & 1 & \\ 10 & 6 & 11 & 16 & 2 & 2 & & & 1 & 1 \\ 11 & 6 & 10 & 7 & 2 & 2 & 1 & 1 & & 1\end{array}$

Table 1 
Figure 1. Top: floor plan of the testing enclosure. Bottom: photograph of an experimenta1 animal in the enclosure during a testing period. 
- $71-$
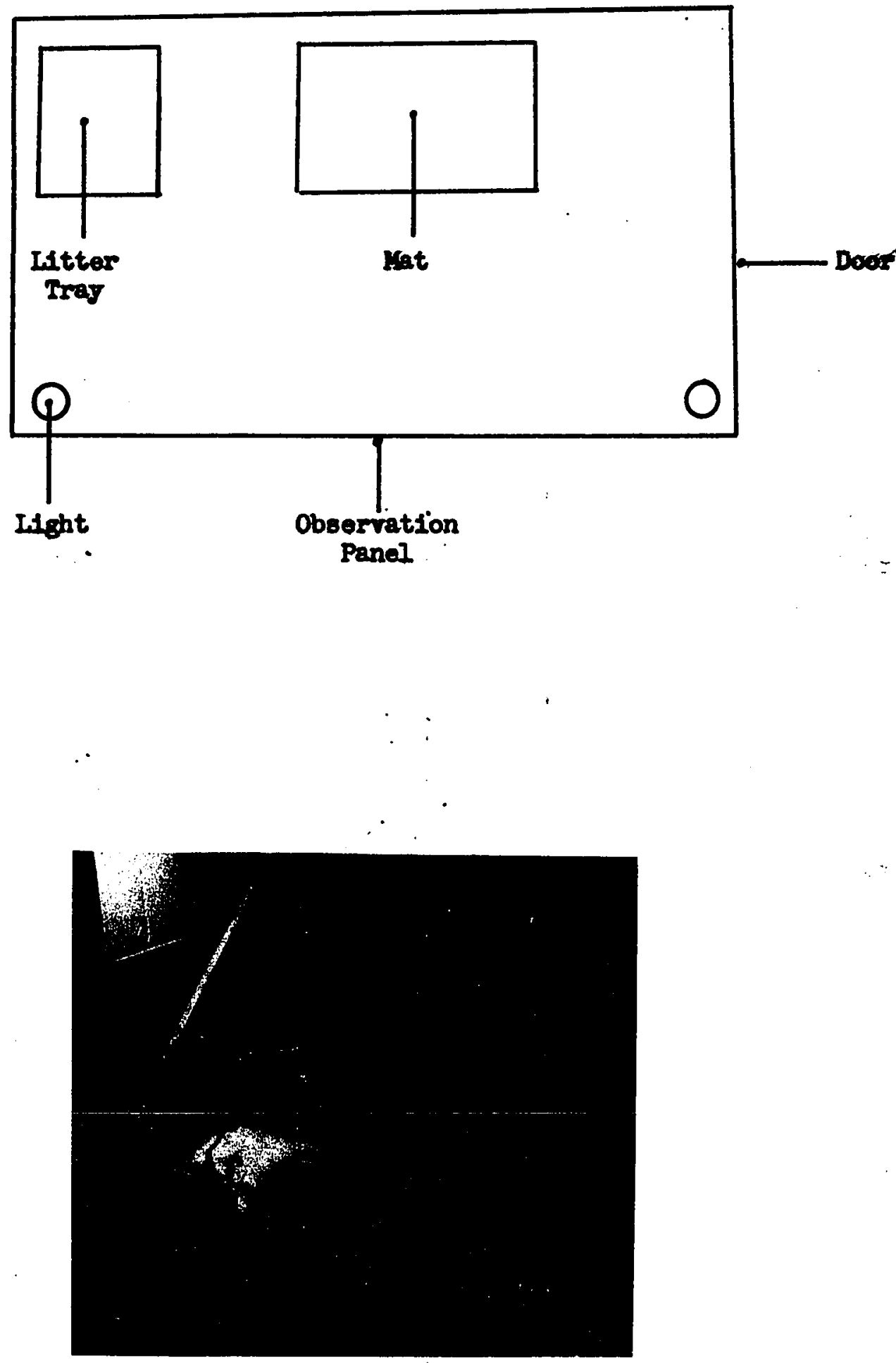

Plgure 1 
- $71-$
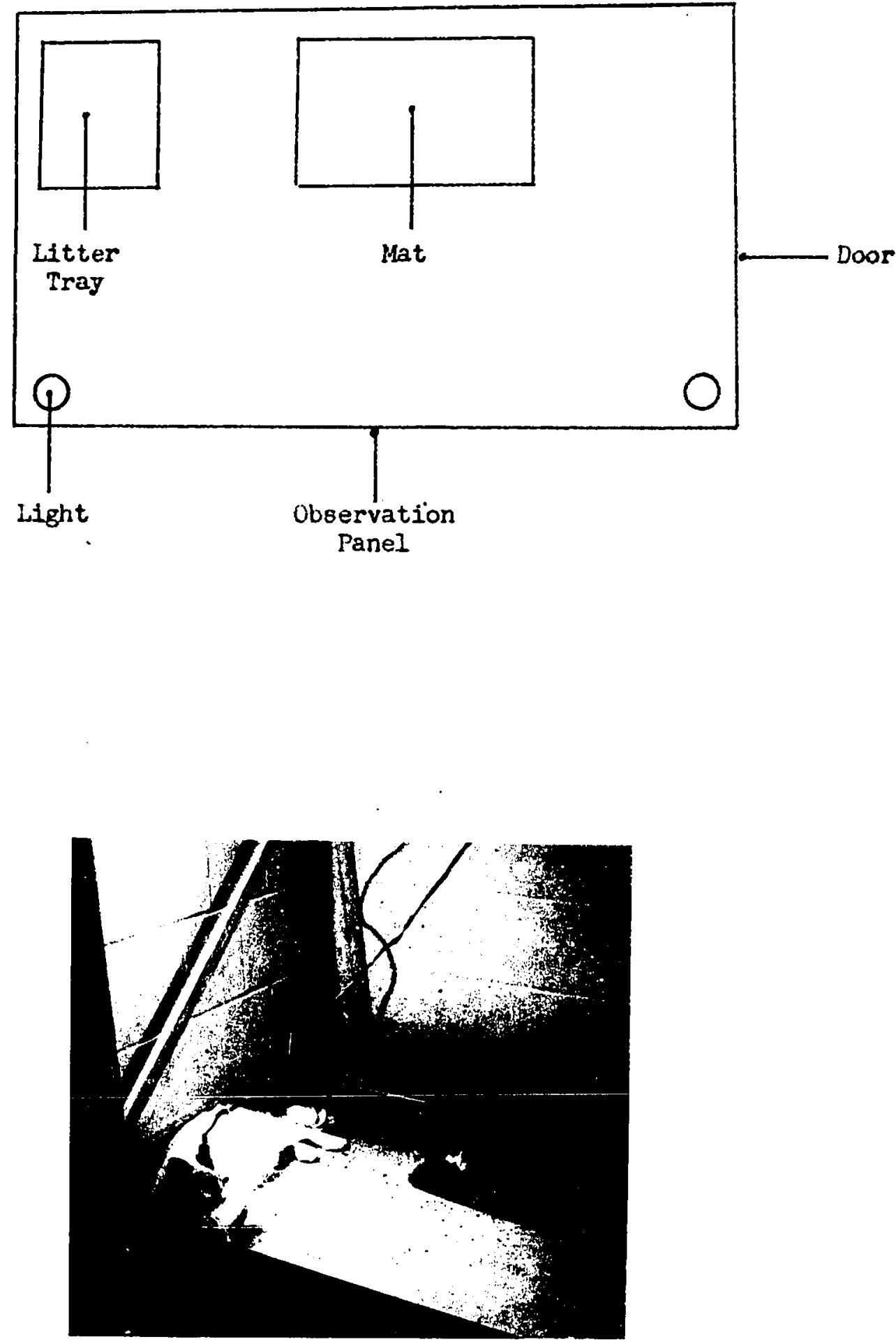

Figure 1 
Figure 2. Block diagram of the recording system used in this study. 


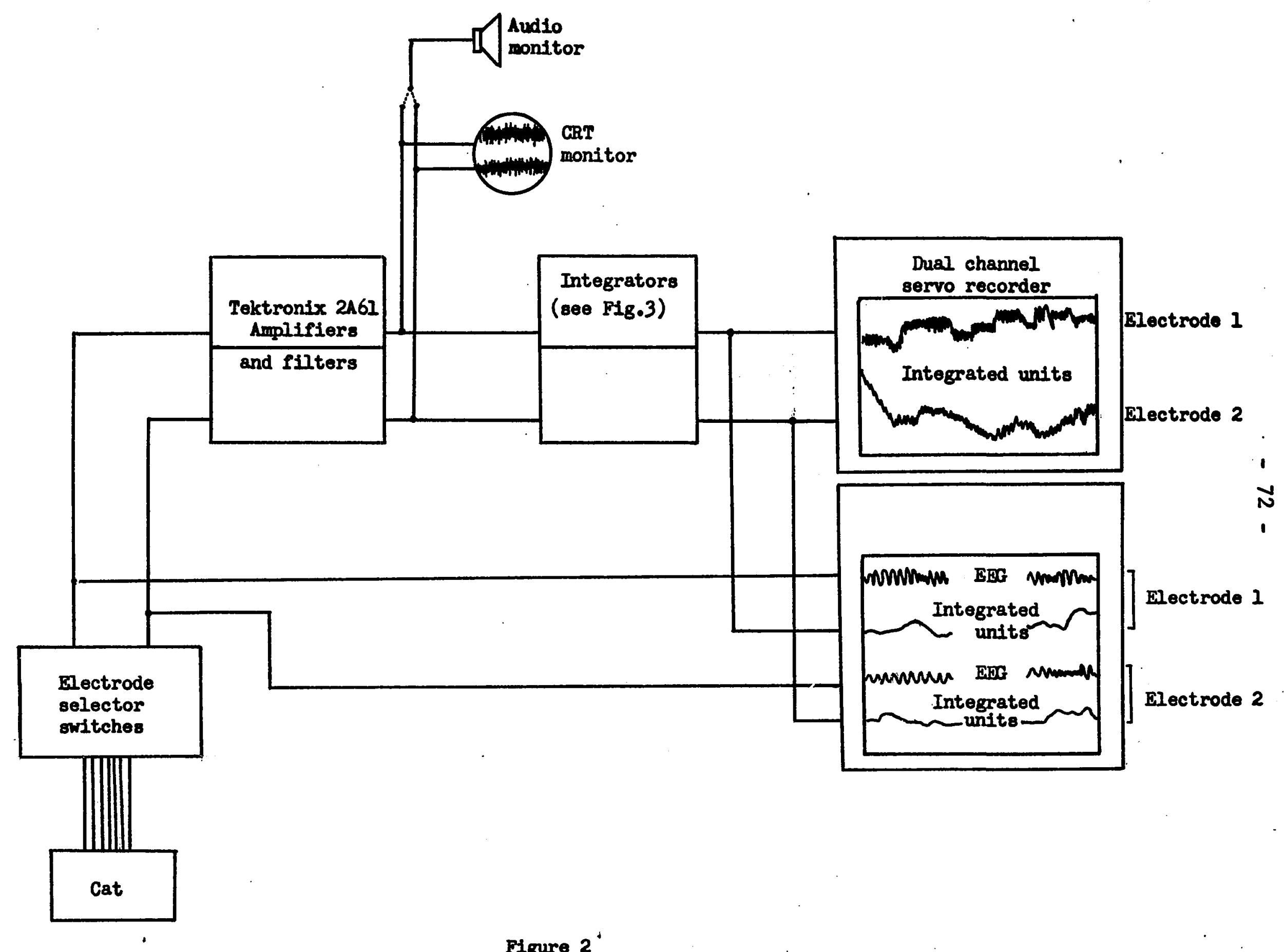

Figure $2^{\circ}$ 
Figure 3. Integrator circuit used in this study, (modified from Weber and Buchwald, 1965). 


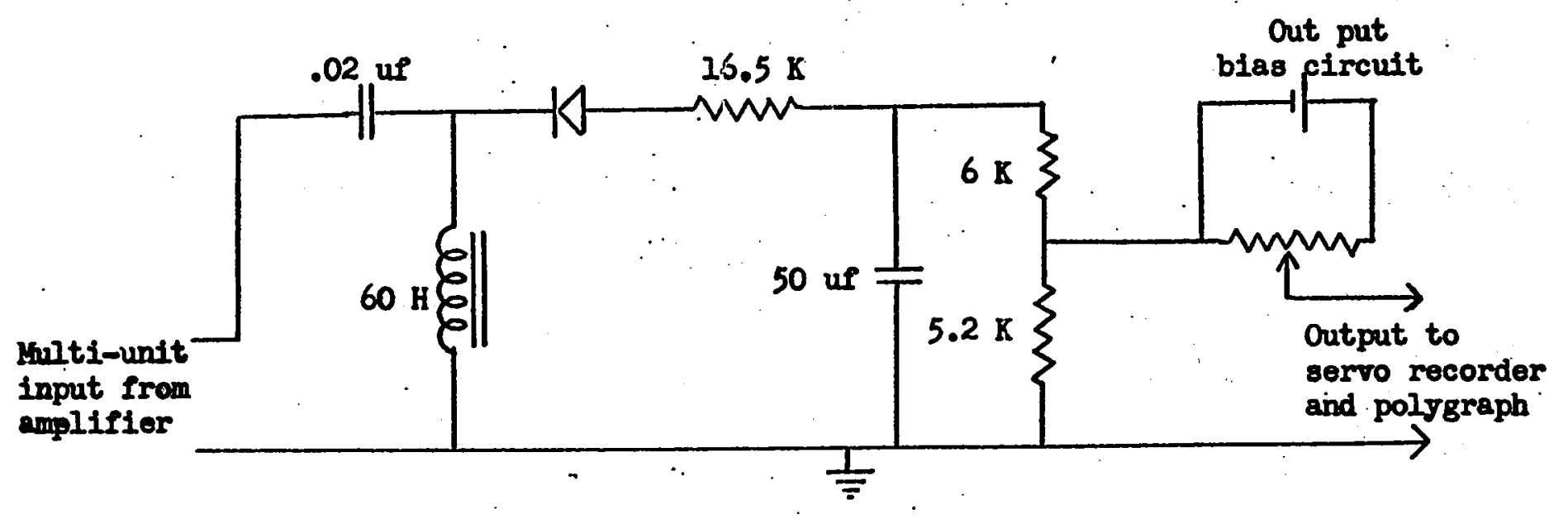

w

Figure 3 
Figure 4. Raw multi-unit (upper channe1), integrated multi-unit (middle channe1) and EEG (1ower channe1) activity from the anterior medial thalamus. Note the correspondence between the integrated activity level and the visible spike envelope. The three samples are not continuous. The middle sample shows an alerting reaction, with a sharp increase (off scale) of the integrated multi-unit channe1 and a desynchronisation of the EEG. 
- $74-$

0
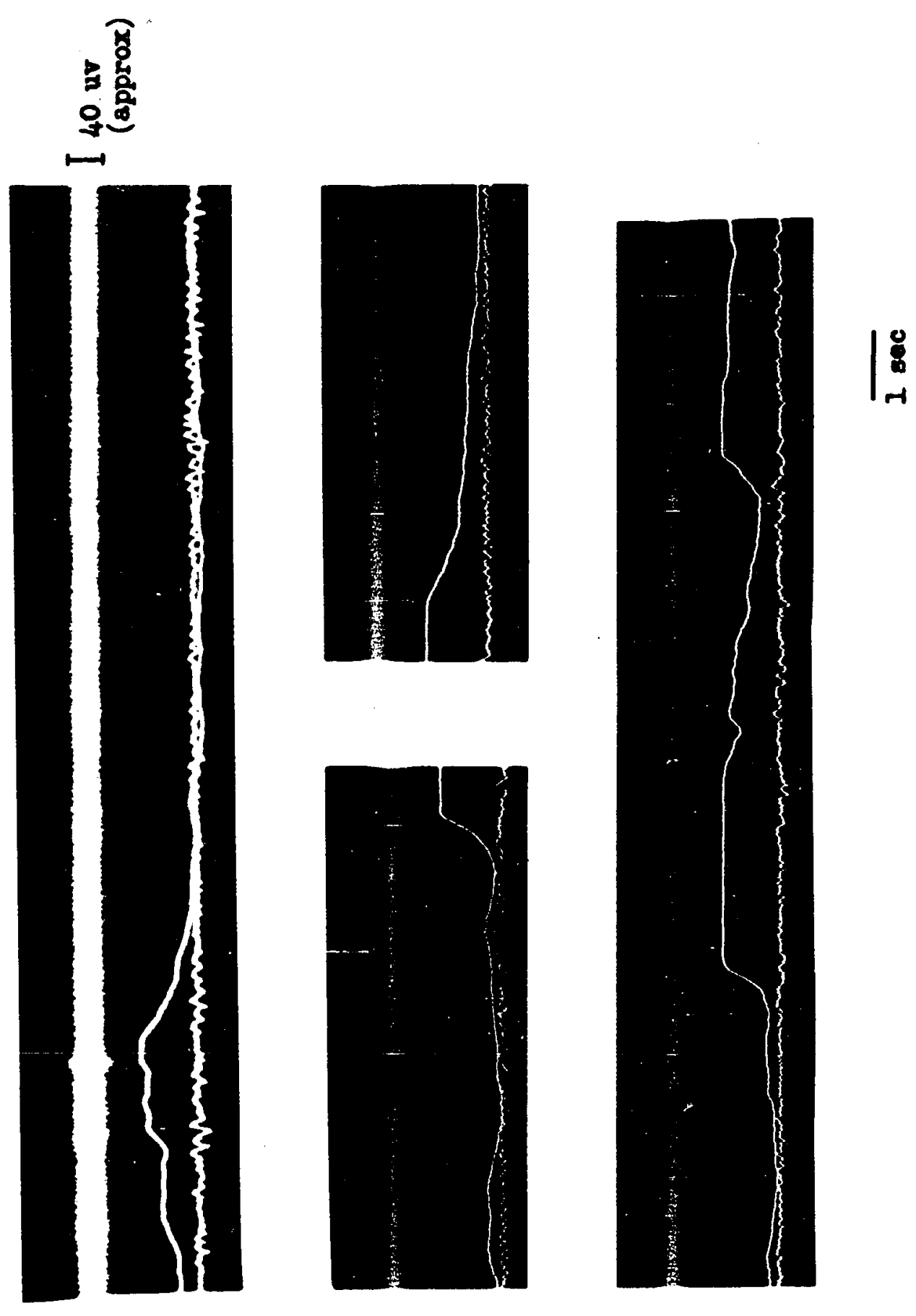

5
8
8 


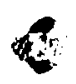

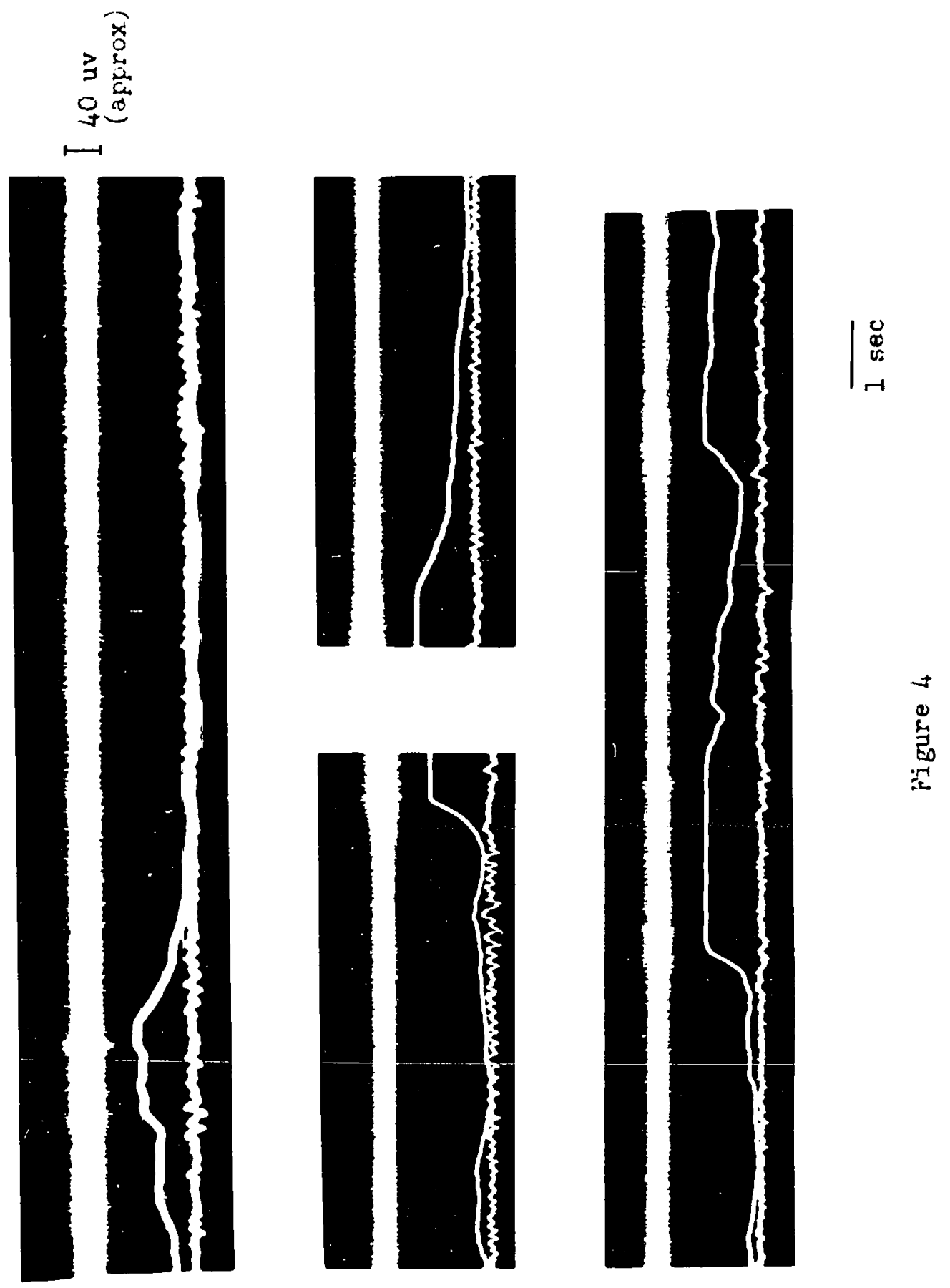


Figure 5. EEG and integrated multi-unit activity from the posterior lateral gyrus. Note the sharp decrease in multi-unit activity which sometimes accompanied the onset of high amplitude s1ow EEG waves (see also Fig. 11). During the two periods of high amplitude slow EEG waves, small ripples in the integrated record indicate that cells in the vicinity of the electrode were firing in bursts, in synchrony with the EEG waves. (The sma11 amplitude of these fluctuations is partly due to the long time constant of the integrator, which attenuates such rapid changes.) 


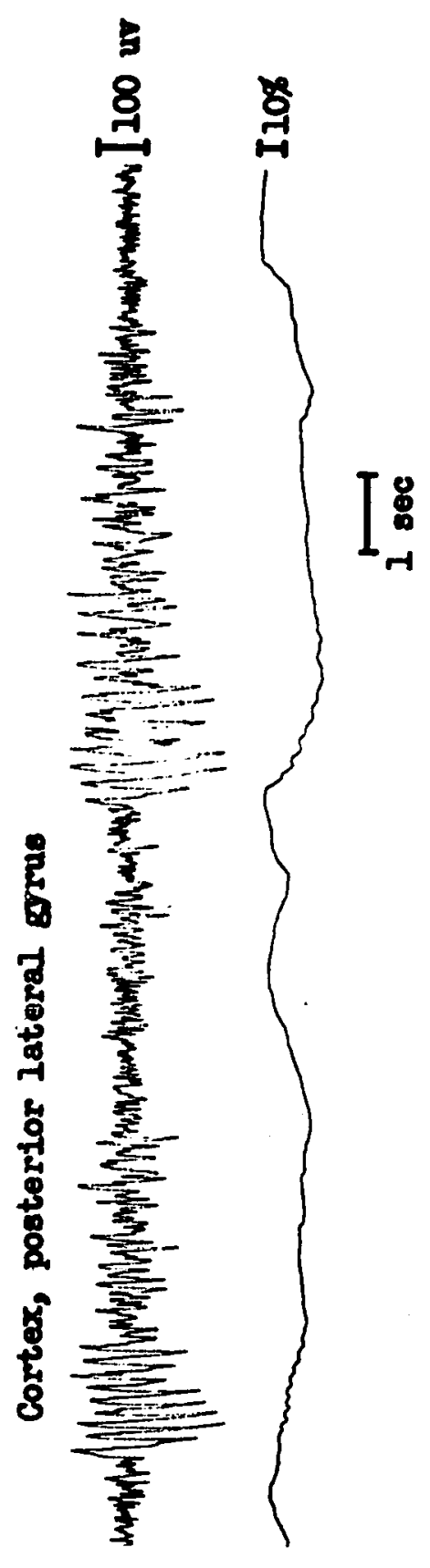

$\frac{8}{8}$

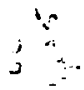


Figure 6. Post-reinforcement synchronisation and arousal linked changes. The horizonta1 bars marked $D$ indicate continuous drinking. A portion of the polygraph record of EEG and multi-unit activity at the end of the first period of drinking is shown below the servo-recorder chart. Note the EEG synchrony and the stable multimunit activity during drinking. The regular fluctuations in multi-unit activity during drinking, most noticable at the reticular formation electrode, with a period of about $2 \mathrm{sec}$, were synchronized with lapping movements. After the first period of drinking, the cat looked up and 1icked its 1ips. After the second period, it stood up, walked across the enclosure, lay down with head up at the first arrow, and remained there for the remainder of the period illustrated. The larger fluctuations during this period were associated either with spontaneous movements or external stimuli. For example, at the second arrow, the cat turned its head and looked up in response to a noise in the room, but did not get up. Note the gradual decrease of baseline levels following these increases in multi-unit activity, and the general similarity of the two channels. 


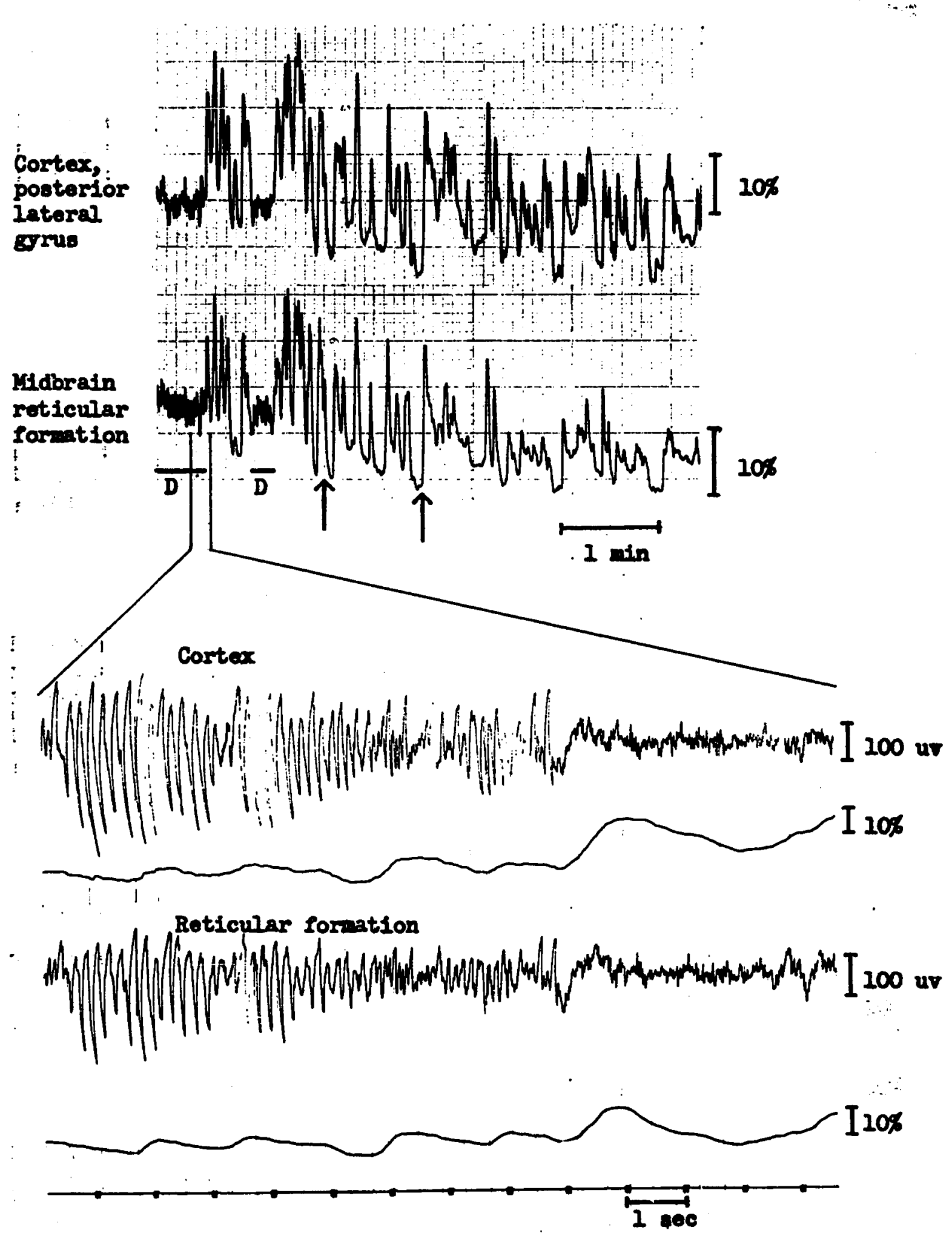

Figure 6 
Figure 7. Effects of anesthetic drug on EEG and multi-unit activity in the reticular formation. The arrows indicate the administration of $50 \mathrm{mg} / \mathrm{Kg}$ (first arrow) and $75 \mathrm{mg} / \mathrm{Kg}$ (second arrow) of sodium pentobarbital intraperitonea11y. The tonic activity drops very rapidly below the normal range after the first administration of nembutal, stabilizing after about $20 \mathrm{~min}$. The EEG still shows continuous high amplitude activity at this stage, and the animal was not clinically anesthetized. The second injection caused the cat to turn and raise its head; the tonic activity in the reticular formation was increased by the procedure and returned to the previous low point after about three minutes. After this, the levels dropped rapidly toward zero. Note that EEG activity it still present when unit activity has almost ceased. 


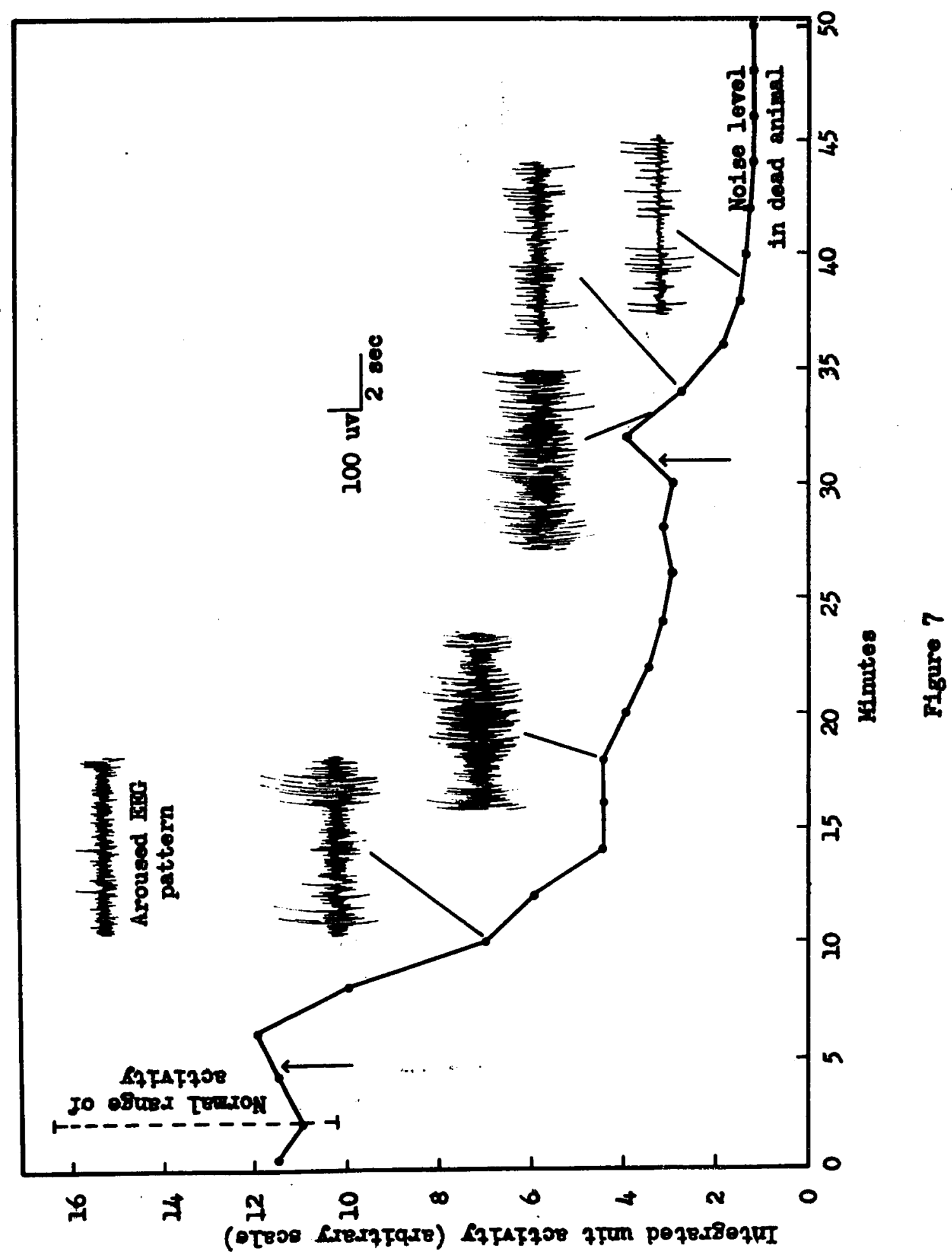


Figure 8. Positive correlations between EEG "desynchronization" and increases in cell discharge rates. The integrated multi-unit activity is shown below the EEG for each electrode. (a) Midbrain reticular formation and anterior thalamus. Solid bar on time channe1 denotes period of noise which alerted the cat. Note that the increase in cell discharge precedes EEG desynchronization by about one second. (b) Pontine reticular formation and ventral tegmentum. The cat was aroused by experimenter calling "puss puss". The EEG and multi-unit changes in this case start at about the same time. 
(a)

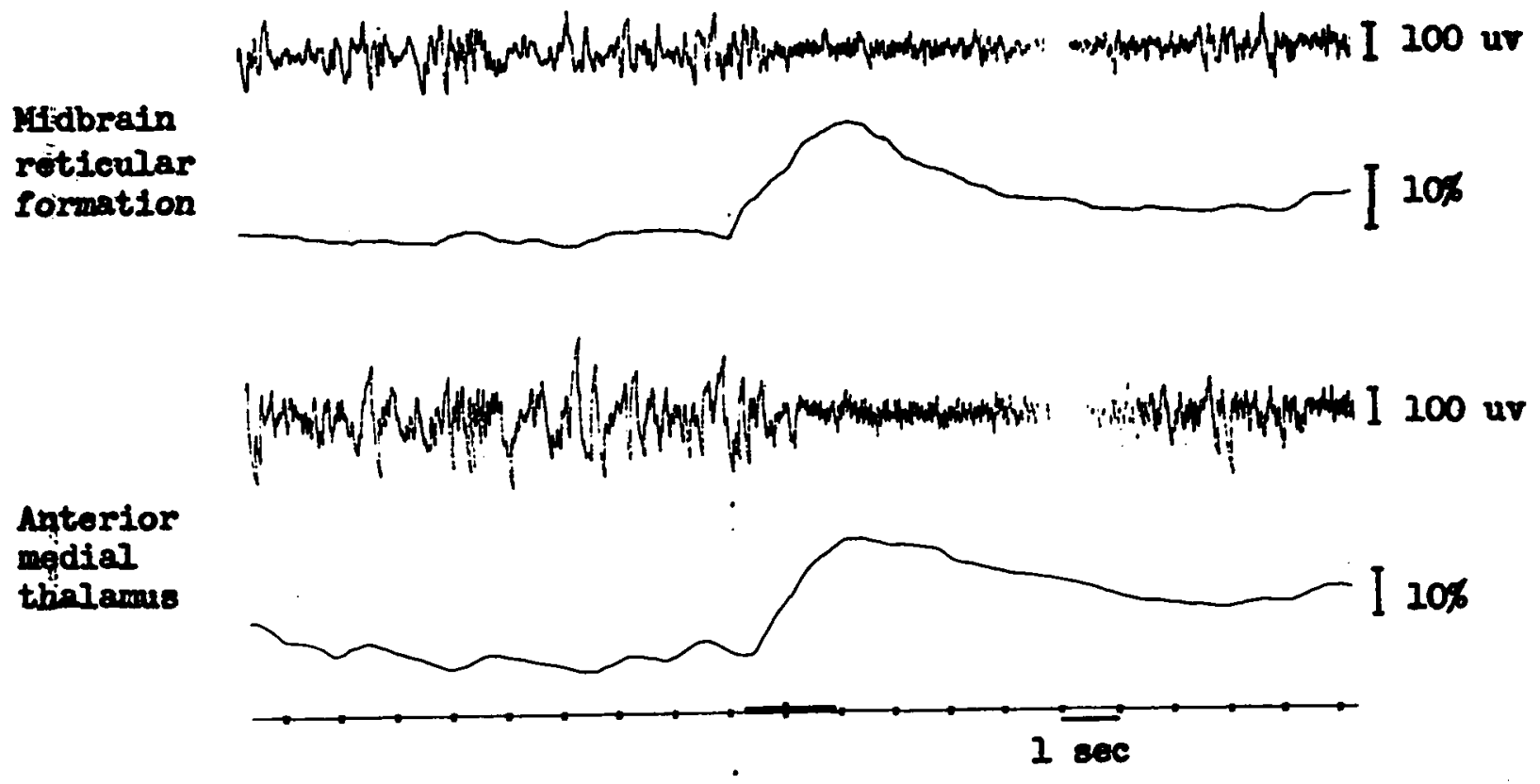

(b)

Pòntine róticular formation

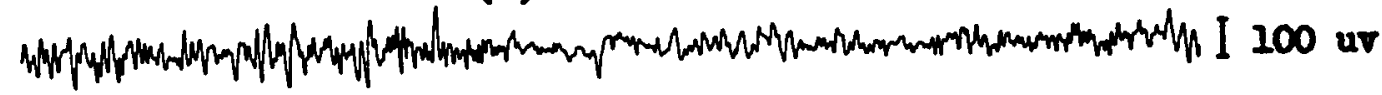

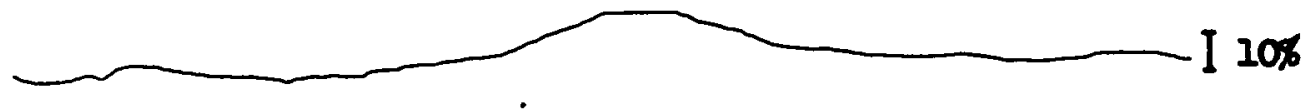

Ventrel

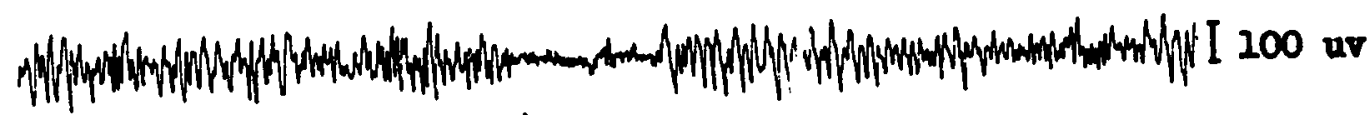
tegmentum

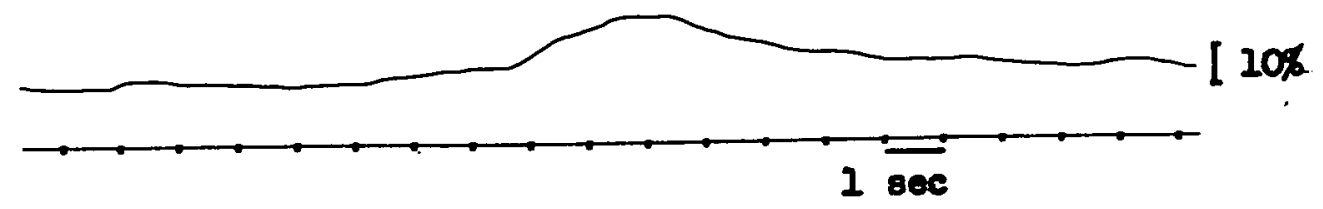

Plgure 8 
Figure 9. Absence of clear correlations between multiunit and EEG activity. The integrated multi-unit activity is shown below the EEG record for each electrode. (a) Cortex and reticular formation. The cat was drinking throughout the period illustrated, and showed the large slow waves typical during drinking (see Fig. 6). Marked changes in the frequency and amplitude of the EEG were not accompanied by changes in multi-unit activity. The sma11 regular fluctuations of the multiunit activity, at a rate of about 2 per sec., were synchronized with the lapping of milk. (b) Anterior medial thalamus and cortex. The cat was sitting quietly with eyes closed.. throughout, and did not respond behaviourally to the quiet call by the experimenter (marked on the time channe1). A1though there are changes in multi-unit levels and EEG waves in both channels, the relationship between the two is not obvious, as it is in Fig. 8 . 
(a)

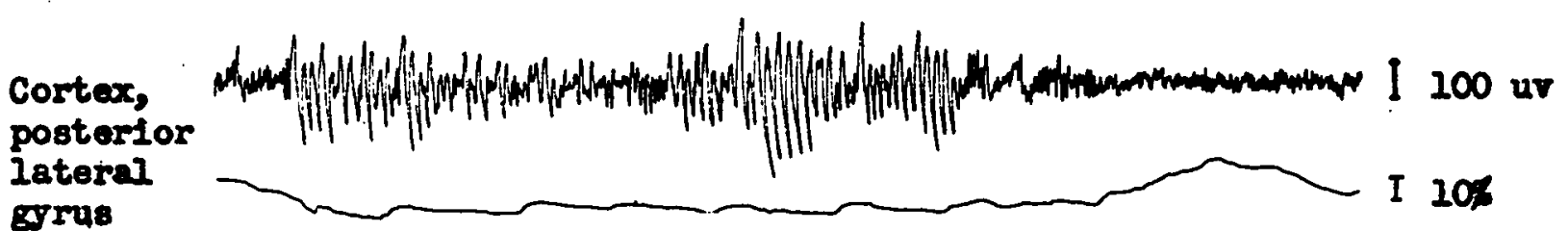

Midbrain

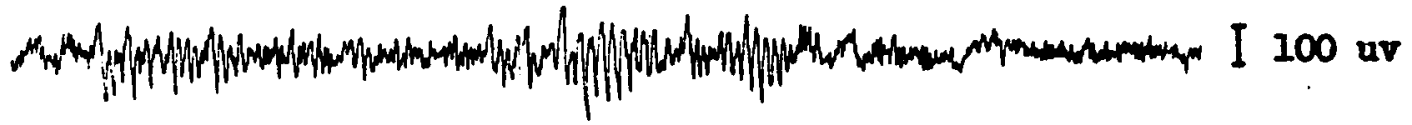
reticualr

formation
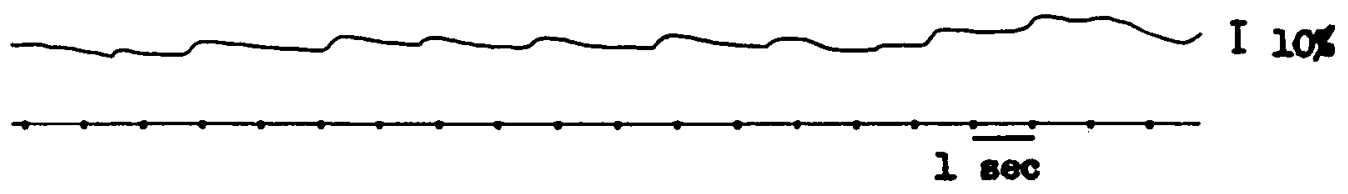

(b)

Anterior medial

thalames

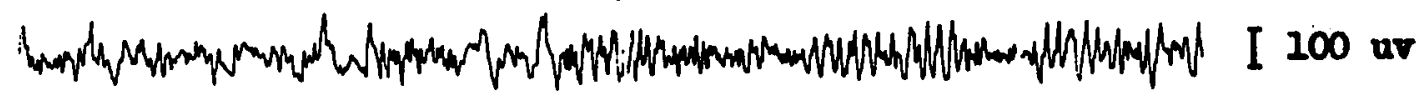

Cortex, anterior lateral

Errus

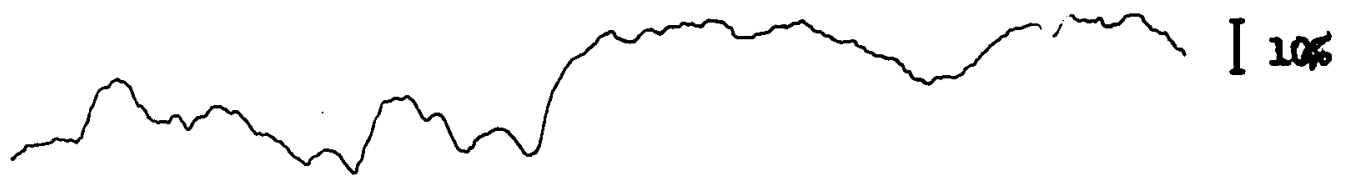

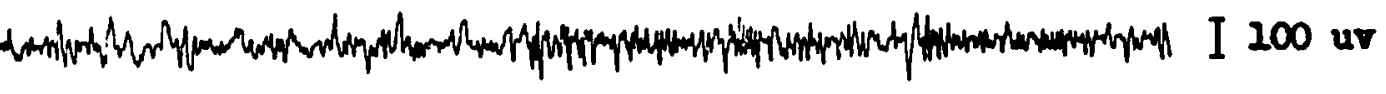

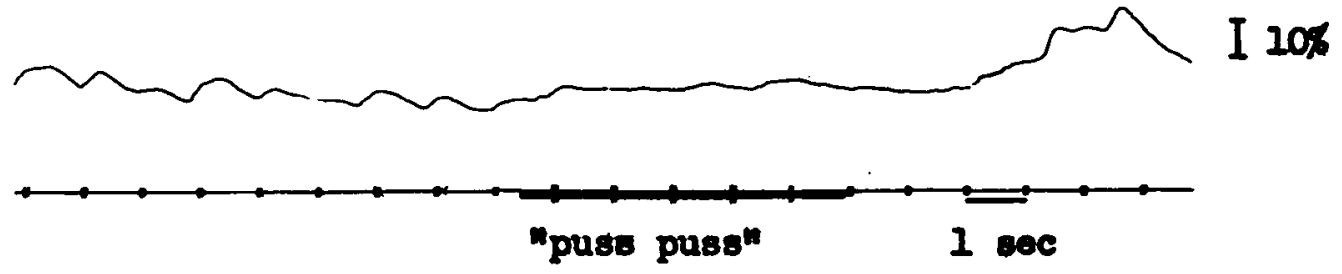

FIgure 9 
Figure 10. Integrated multi-unit activity of cortex and anterior medial thalamus. The cat was lying down throughout. At 0 min., the experimenter entered the enclosure briefly, which caused a large increase in tonic activity in both channels. The activity then declined gradually during the next two minutes, and then more slowly during the subsequent eight minutes. A11 the larger simultaneous increases in both channe1s in the remainder of the rec ord were related either to spontaneous movements, or to external stimuli. For example the sharp increase at $3.0 \mathrm{~min}$. occurred when the experimenter called "puss puss" softly. Note the sharp decreases in thalamus activity during the period of relatively quiet cortical activity between 6 and 7 min., 8 and 9 min., and at 10 min. This type of activity occurred during a period of quiet background noises to which the cat had been exposed repeatedly, and did not respond behavioural1y. The horizontal bar marks the time from which Fig. 11 is taken. 





Figure 11. EEG and integrated multi-unit activity in the posterior lateral gyrus and anterior medial thalamus, during the period corresponding to the black bar in Fig. 10. At the dotted line, the cat, which was sitting quietly, closed its eyes briefly. At this point in the record, slow waves appear at both electrodes and there is a sharp dip in the cortical multi-unit record at the same time. Note also the small fluctuations in the multi-unit record, indicating synchronous cell discharge. 


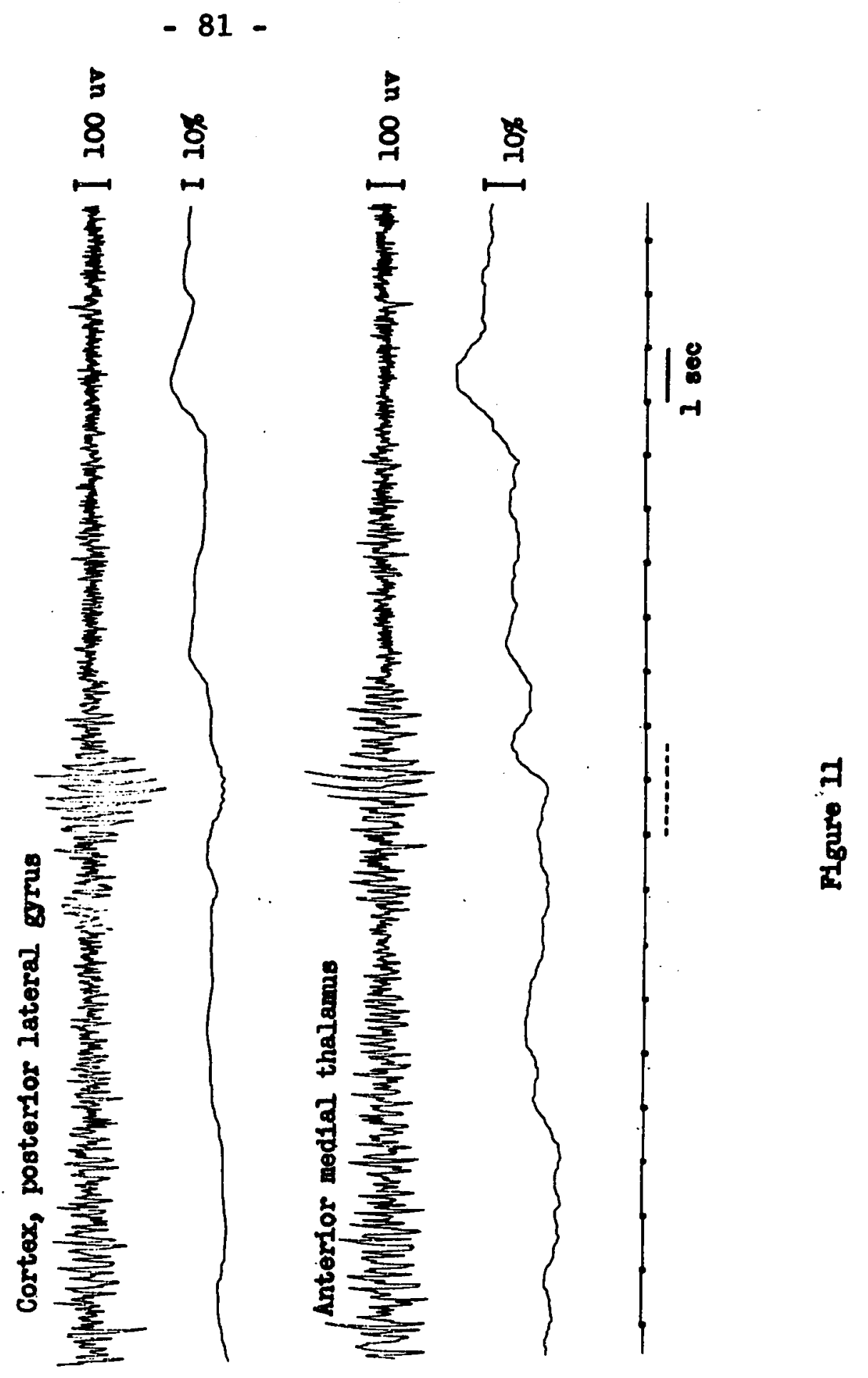


Figure 12. Integrated multi-unit activity from the inferior colliculus (IC) and midbrain reticular formation (RF). Note that IC activity tends to fluctuate about the same baseline throughout, while the $\mathrm{RF}$ baseline level varies. These variations are correlated with the behaviour of the cat. At time 0 , the cat rose from a sitting position and walked toward the litter tray. The record during this time shows a gradual rise in RF activity. Between 0 and 1 min., the cat started pawing at the litter in the tray, and the IC record shows increased activity in response to the sounds thus produced. The increase in the IC activity at $3 \mathrm{~min}$. is also in response to pawing sounds. The cat lay down at $3.8 \mathrm{~min}$., and the IC record returns to its typical "quiet waking" or slow sleep baseline leve1, and maintains it up to $16.5 \mathrm{~min}$. During this time, however, the RF baseline drops quite rapidiy for 2 min., and then more slowly until the slow sleep baseline is reached (level at 15.0 min.). The larger brief increases in $R F$ activity during this period accompany head movements or postural adjustments. Between 16.5 and 18.5 min., the experimenter entered the enclosure and stroked the cat, and the RF activity increases. Although the $\mathrm{RF}$ activity is variable during the stroking period, it never approaches the slow sleep baseline. The increase in IC activity during this period again appeared to be largely dependent on the auditory input, and when the ears of the cat were covered (at 17.0 and 17.5 min.) activity dropped we11 below the resting baseline. Note also that after the period of stroking, (20 min. to the end) the RF activity remains at a moderately high level, while the IC activity has returned rapidly to its normal baseline. 


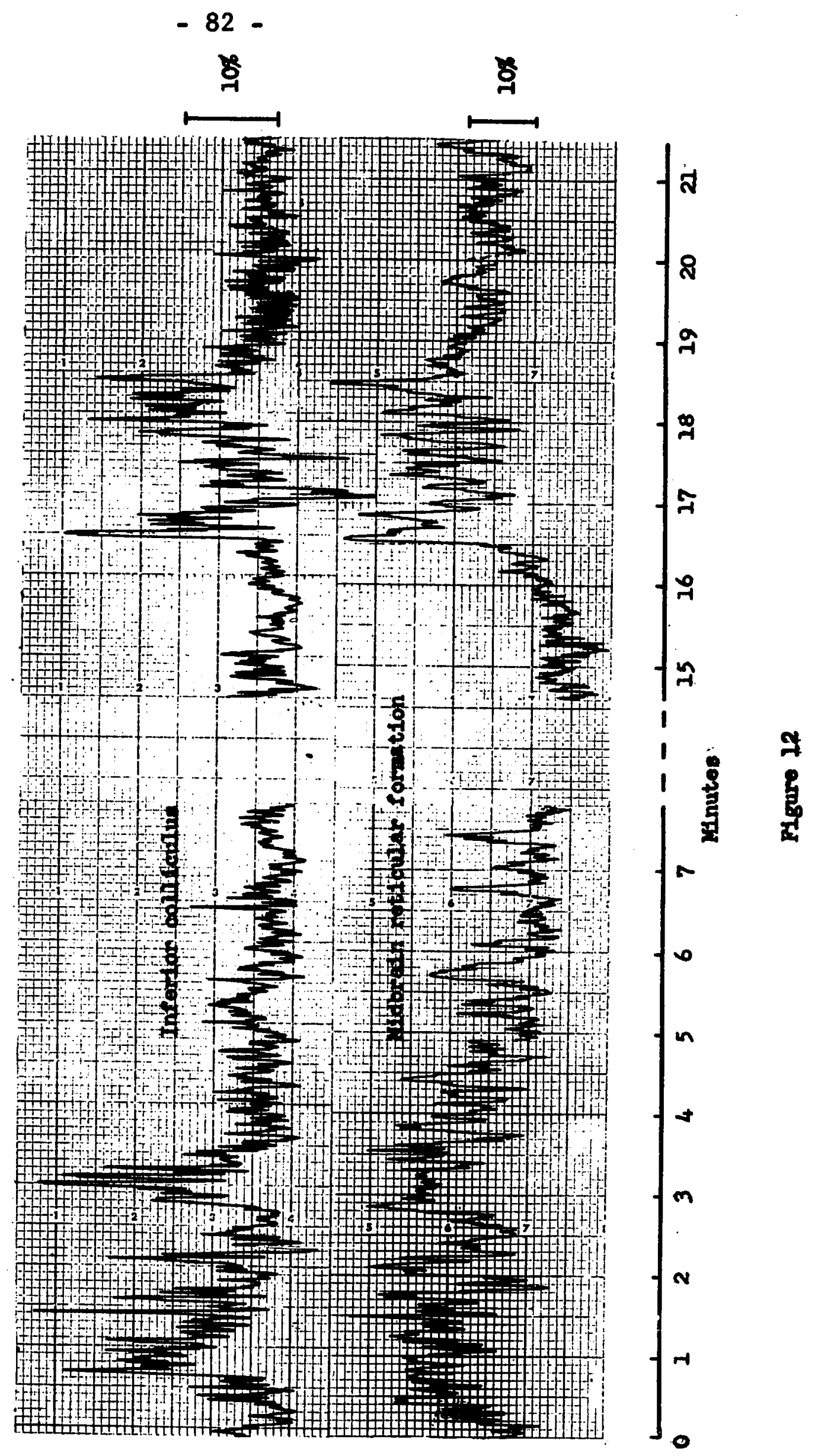


Figure 13. Integrated multi-unit activity from the lateral geniculate nucleus and reticular formation. At the beginning of the record, the cat was lying down, alert, looking around, and shifting positions, after a period of activity. At 2.0 min., it put its head down, and remained in this relaxed position for the rest of the record, with eyes sometimes open, sometimes closed. The baseline level of lateral geniculate activity shows little change during this period. The reticular formation activity, however, drops rapidiy at first, and then more slowly toward the slow sleep baseline. At $4.8 \mathrm{~min}$. the cat squeezed its eyes closed, and both channels show increased activity. At 6.6 min., the cat, which had been lying very quietly, shifted its position slightly, but did not open its eyes. The large increase in reticular formation activity was not reflected in the lateral geniculate channe1. The polygraph chart for this section of record, marked by the horizontal bar, is shown in Fig. 14. The increase in reticular formation activity at $12.0 \mathrm{~min}$. was in response to a noise in the laboratory, though there was no behavioural response. The lower channel leads the upper by $6 \mathrm{sec}$. (one small division) in this figure. Note that the reticular formation gain is higher than in other figures. 


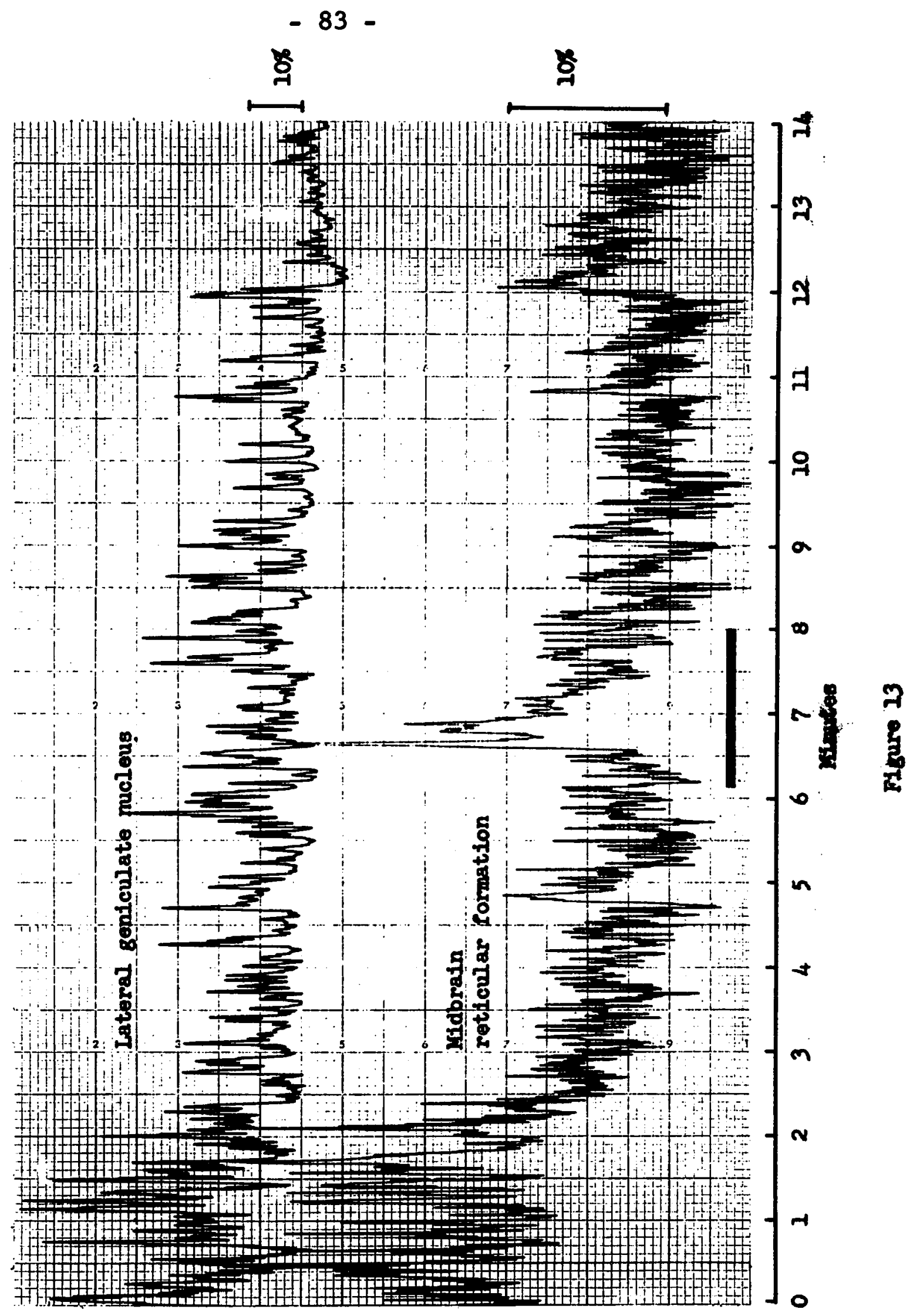


Figure 14. EEG and multi-unit activity in the lateral geniculate nucleus and the midbrain reticular formation during the period marked by the black bar in Fig. 13. The cat was resting and shifted or moved occasionally. The large increases in reticular formation multi-unit activity which accompanied a postural shift in the resting cat is not reflected in the lateral geniculate multi-unit activity (though the EEG shows low amplitude fast activity for about 40 seconds). 
- 84 -

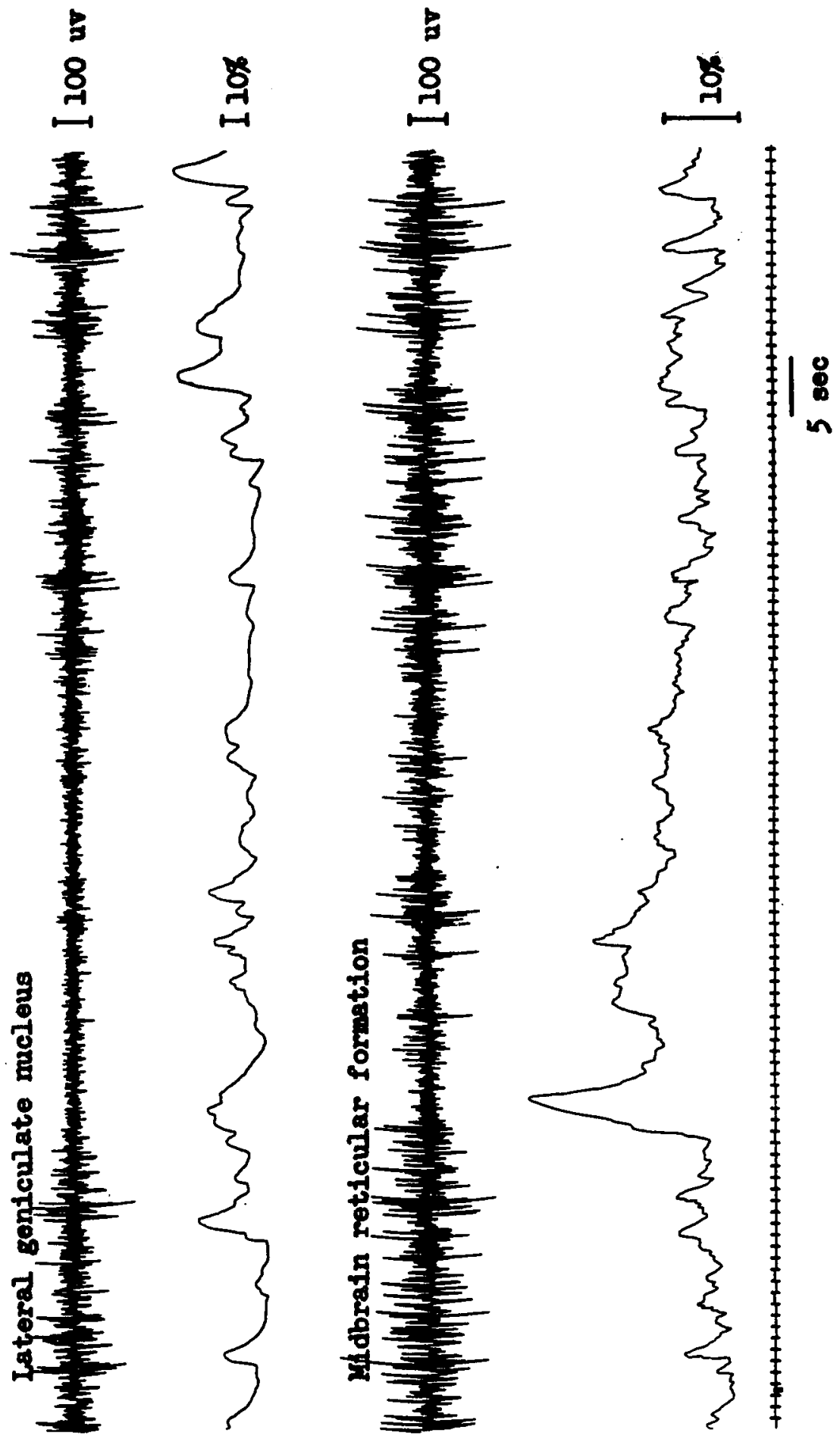

章 
Figure 15. Integrated multi-unit activity in arousa1-related areas in one cat during petting, traced from reduced reproduction of original records. (a) Pontine reticular formation, (b) ventra1 tegmentum, (c) posterior lateral gyrus, (d) and (f), midbrain reticular formation (same electrode) and (e) anterior medial thalamus. (a) and (b) were recorded simultaneous1y, as were (b) and (c). At the first marker on each record, the experimenter entered the enclosure, at the second mark began to stroke the cat gently, and at the third mark, one minute later, left the enclosure. This cat remained lying down, though attentive, when the experimenter entered the enclosure, and usually did not get up to approach the experimenter until the middle of the stoking period. Note the similarity of al1 channels. The entrance and exit of the experimenter evoked large increases in tonic activity in arousal-related areas. The entrance of the experimenter, which usually produced the largest increases, was accompanied by very little increased overt motor activity (no more than head turning). Vertical scale, $10 \%$. 


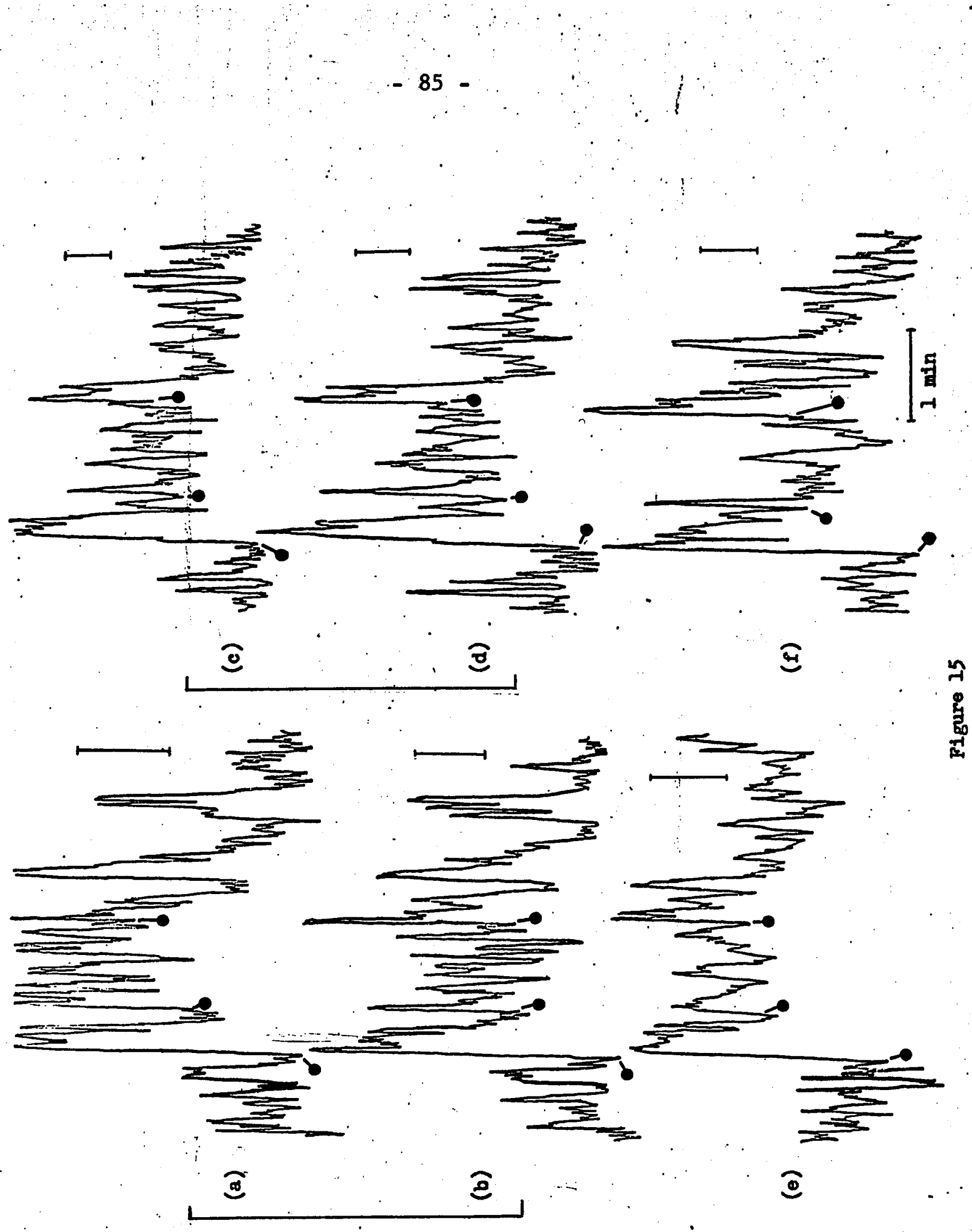


Figure 16. Cortical multi-unit activity. The two channels are very similar, but not identica1. At 0 min., the cat (which had been grooming) lay down and remained 1ying down, but quite alert, throughout this record. The increases between 0 and 1 min. occurred as the cat played with its paw, and bit playfully at the floor. At time 2, the door of the enclosure was opened very briefly, and the cat looked up and turned its head toward the door. A11 the large increases in multi-unit. activity had similar behavioural:correlates. 


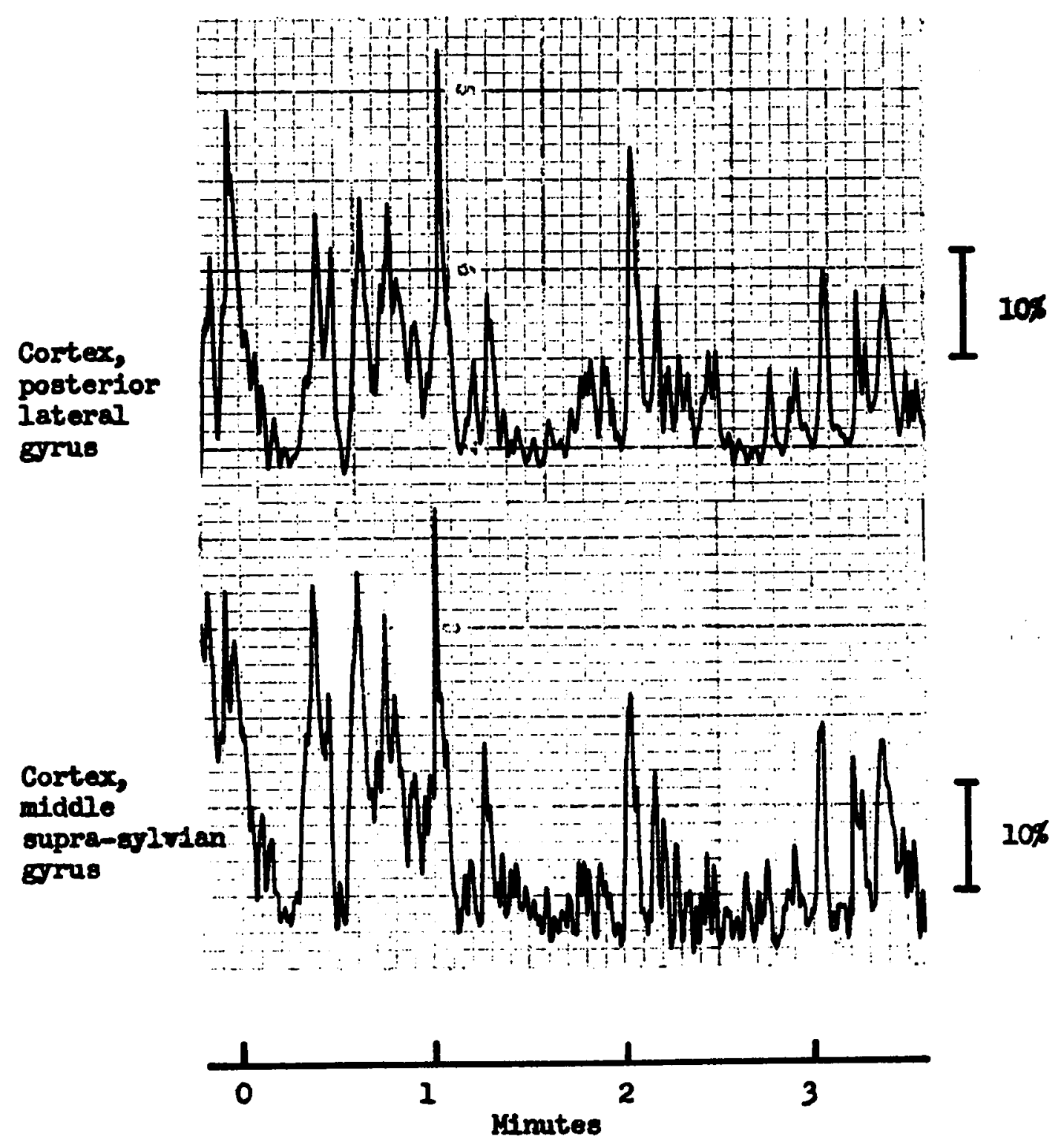

PIgure 16 
Figure 17. Integrated multi-unit activity in the pontine reticular formation and ventral tegmentum during aroused behaviour. From the beginning of the record to $1.8 \mathrm{~min}$. the cat was sitting down and alert. The cat subsequently oriented toward a series of noises in the laboratory, and stood up at $3.8 \mathrm{~min}$. Each of the large increases in multi-unit activity which occurred sumultaneously in both channels (marked by arrows) accompanied orienting responses to sounds. These large increases, and the slower decline in activity which followed them, appeared in both channels. There are considerable differences in the detailed variations in multi-unit activity, however. These differences are much greater than the differences between two cortical electrodes (see Fig. 16). The lower trace is retouched. See also Fig. 18 which shows the polygraph record for the period marked by the horizontal bar. 




PIgure 17 
Figure 18. EEG and multi-unit activity in the pontine reticular formation and ventral tegmentum during the period marked by the horizontal bar in Fig. 17. Note the differences in the multi-unit activity of the two channe1s. 
- $88-$
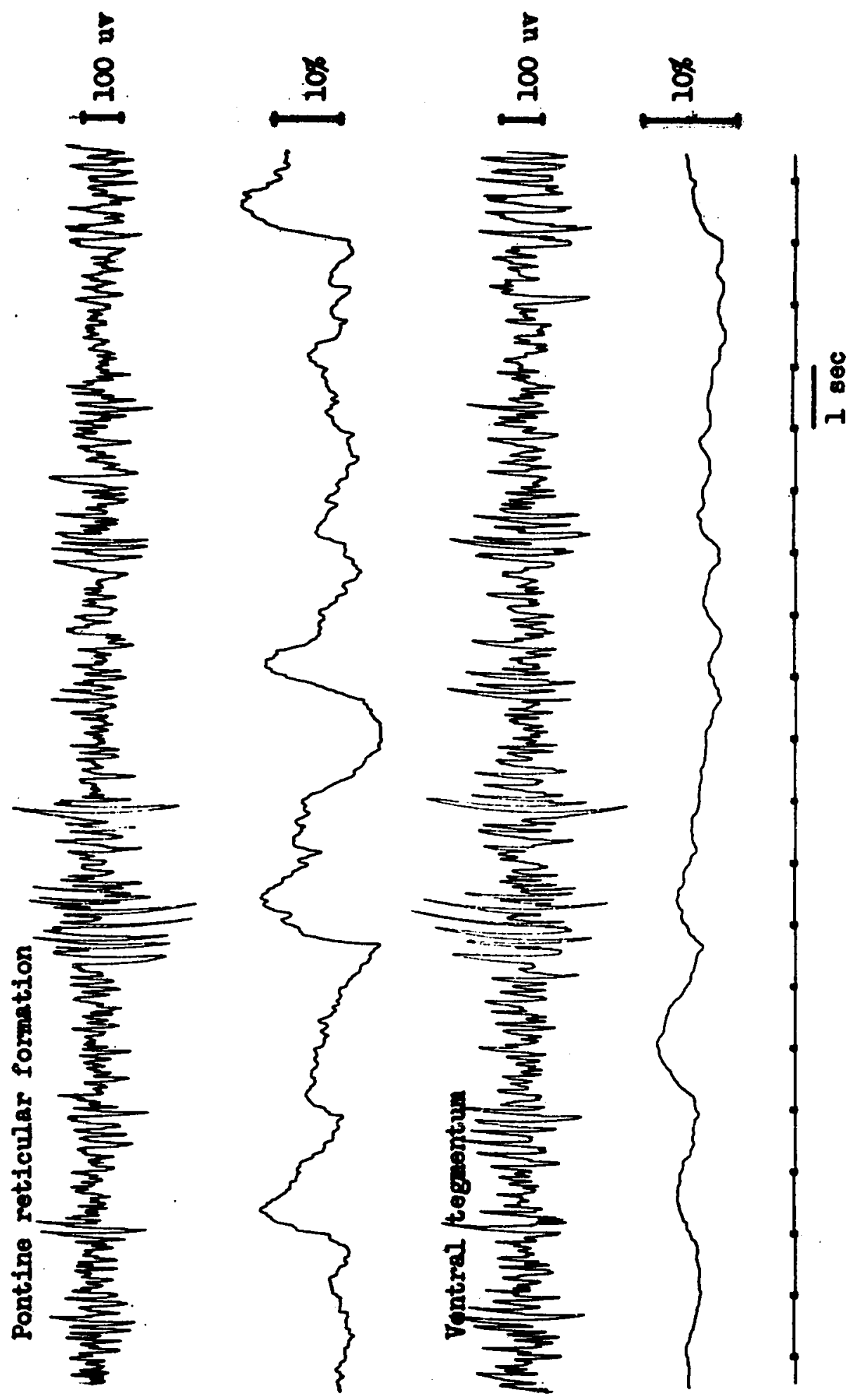

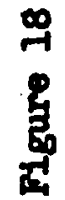


Figure 19. Increases in multi-unit activity evoked in the lateral geniculate nucleus and inferior colliculus by sensory stimuli. Responses to sweeping a flashlight across the visual field and to a $700 \mathrm{~Hz}$ tone are shown. Immediate and sustained responses to visual stimuli occur in the lateral geniculate, and to auditory stimuli in the inferior colliculus. The cat was lying down, awake, throughout these sequences. The background activity on which the evoked changes are imposed is typical of these areas in a resting or sleeping cat. Note the small long latency response to light in the inferior colliculus, and the brief bursts of activity in the geniculate at the onset and termination of the tone. Such responses, with different latencies and durations, were often seen. The transient lateral geniculate response at the onset of sound were sometimes correlated with orienting movements. Other lateral geniculate responses, and the inferior colliculus response tó visual stimulation may have reflected changes in sensory input resulting from orienting movements, or a general arousal effect produced by the original stimulation. The effects, however, were not reproducible as were the specific sensory responses: 

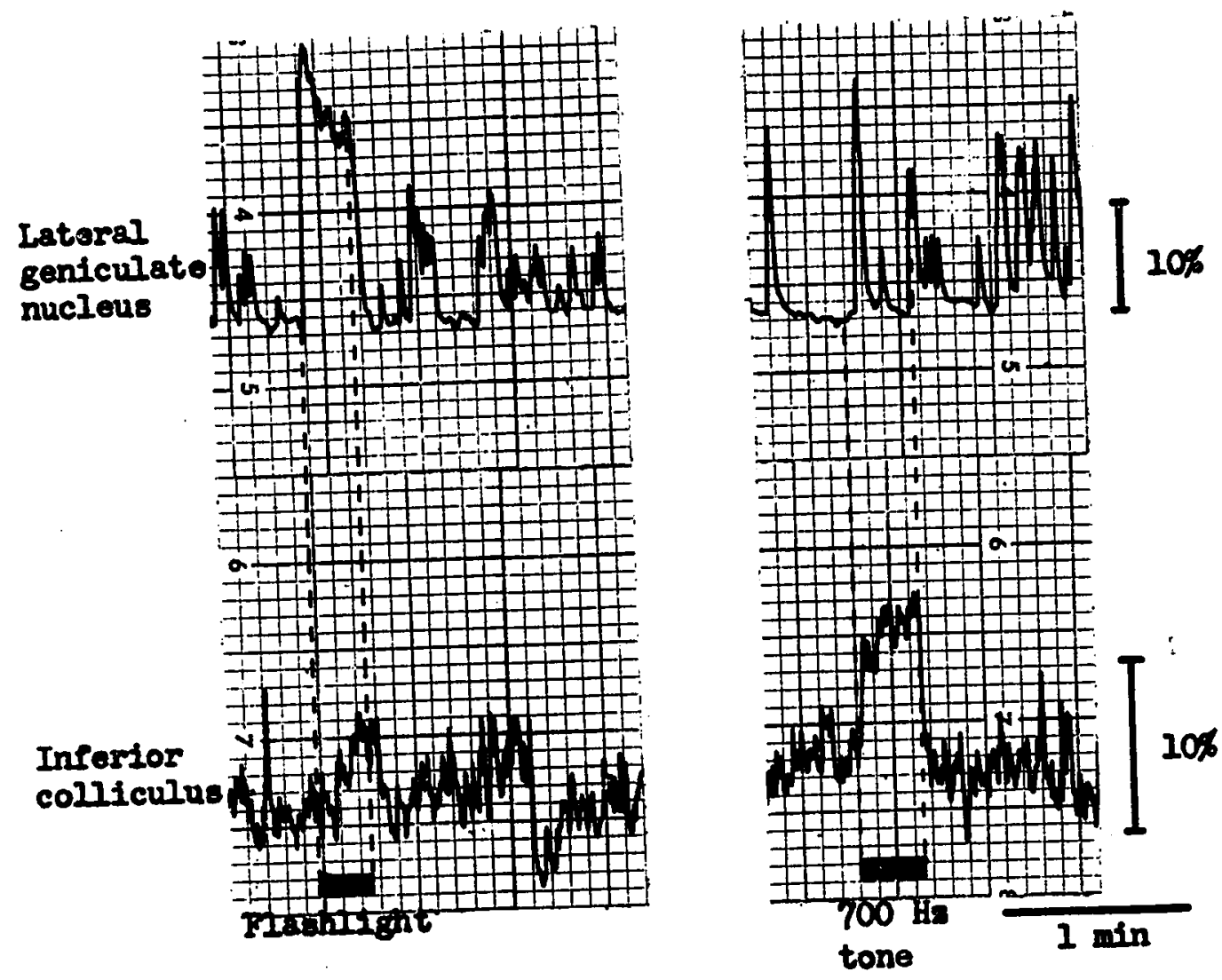

Plgure 19 
Figure 20. Multi-unit activity from the lateral geniculate nucleus and:inferior colliculus during arousal, slow sleep, and paradoxical sleep. It is difficult to distinguish quiet resting from slow sleep multi-unit activity in these areas. The typical appearance of the geniculate, with bursts of activity superimposed on a very quiet background, and the drifting, within a narrow range, of the inferior colliculus baseline levels, are similar during the quiet resting phase and slow sleep phase. These variations in activity of the two areas often occurred in the absence of any apparent change in the stimulus situation or the behaviour of the cat. During paradoxical sleep, the baseline activity in the latera1 geniculate nucleus is elevated and the bursts of increased activity are more frequent. The inferior colliculus shows sharp decreases of activity during paradoxical sleep; these decreases tend to occur simultaneously with bursts of increased activity in the geniculate (or in arousal-related areas). 


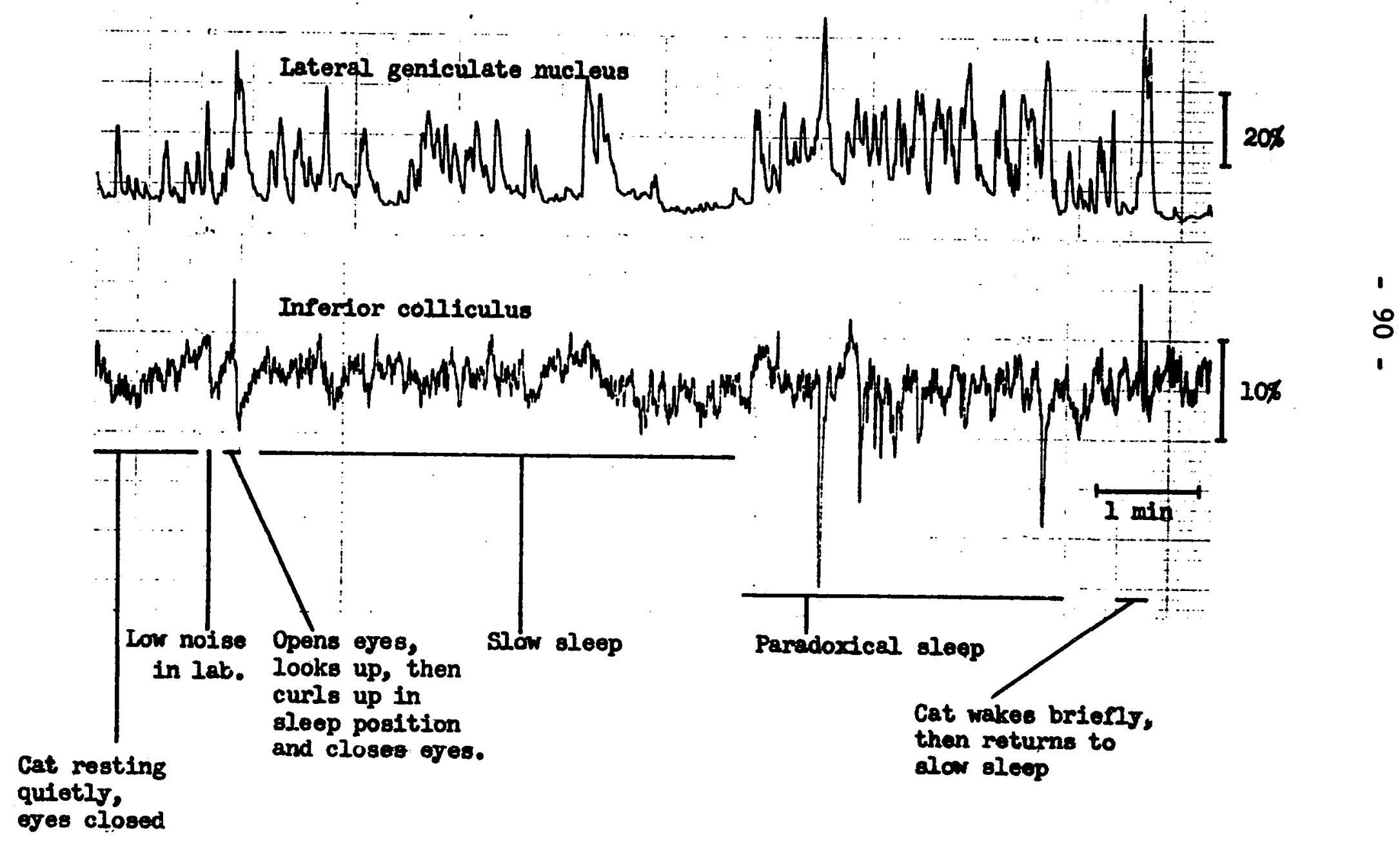


Figure 21. Multi-unit activity in the reticular formation during sleep and paradoxical sleep. The EEG samples from the pontine (PRF) and midbrain reticular formation (MRF) correspond to the lettered segments of the upper multi-unit record. The cat was asleep throughout the record, except for a period of about ten seconds towards the end of the paradoxical phase, at time $8.5 \mathrm{~min}$., when the cat raised its head and opened its eyes briefly, and then went to sleep again. This behaviour was often seen towards the end or at the end of a paradoxical sleep phase (see Fig. 20), and was accompanied, as it is here, by large increases in multiunit activity in arousa1-related areas. The EEG from both electrodes shows the fast low-amplitude activity characteristic of paradoxical sleep. Note the relatively steady multi-unit baseline activity during slow sleep, the gradual rise and fall of activity at the beginning and end of the parâdoxical phase, and the irregular bursts of very intense activity. During these bursts of activity, twitching of the extremities, a typical occurrence during paradoxical sleep, was sometimes, but not always, observed. 

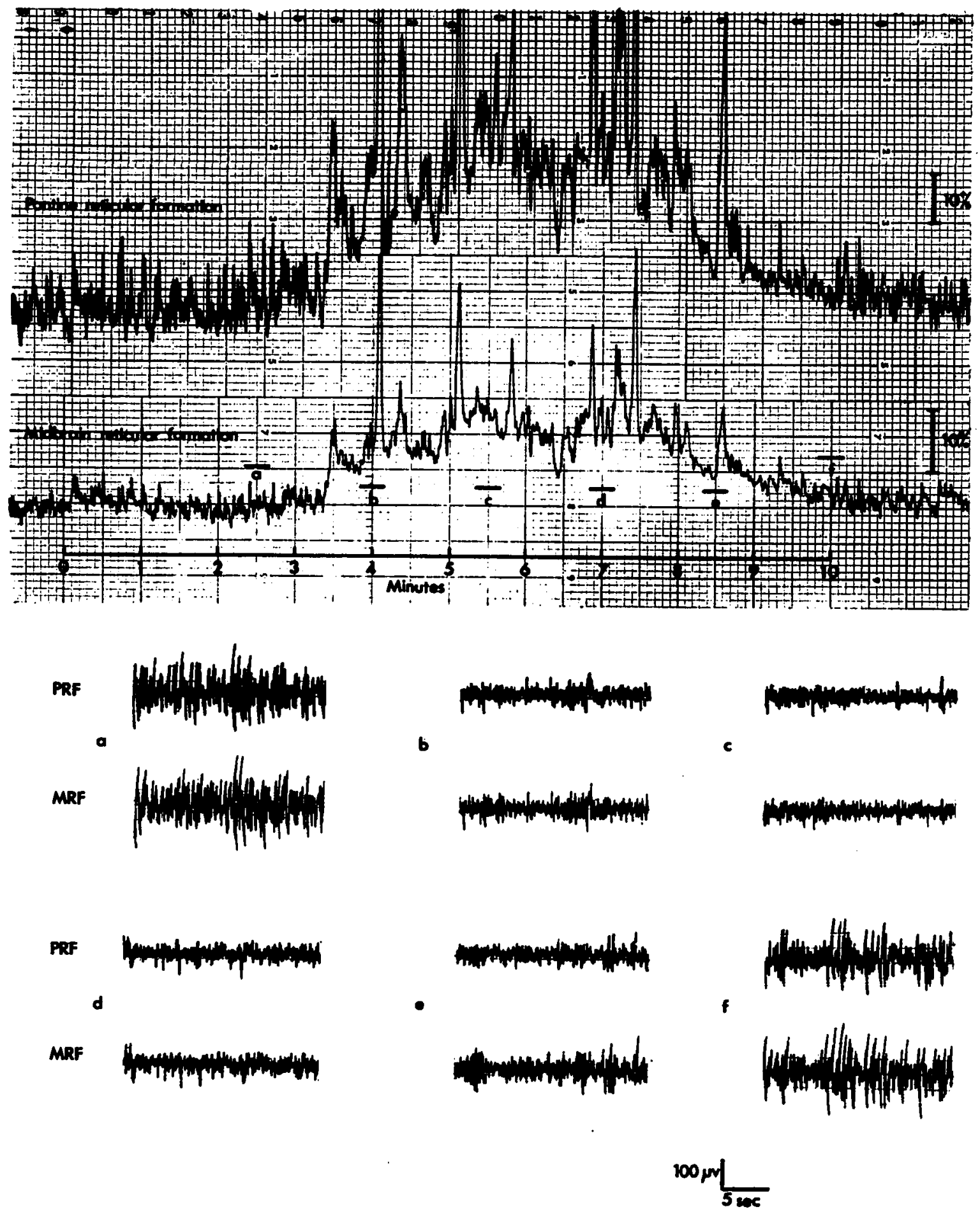

Pigure 21 
Figure 22. Representative sections showing thalamic, and reticular formation electrode tracts, and the one ventral tegmental placement. The arrows show the location of the electrode tip. 
- 92 -
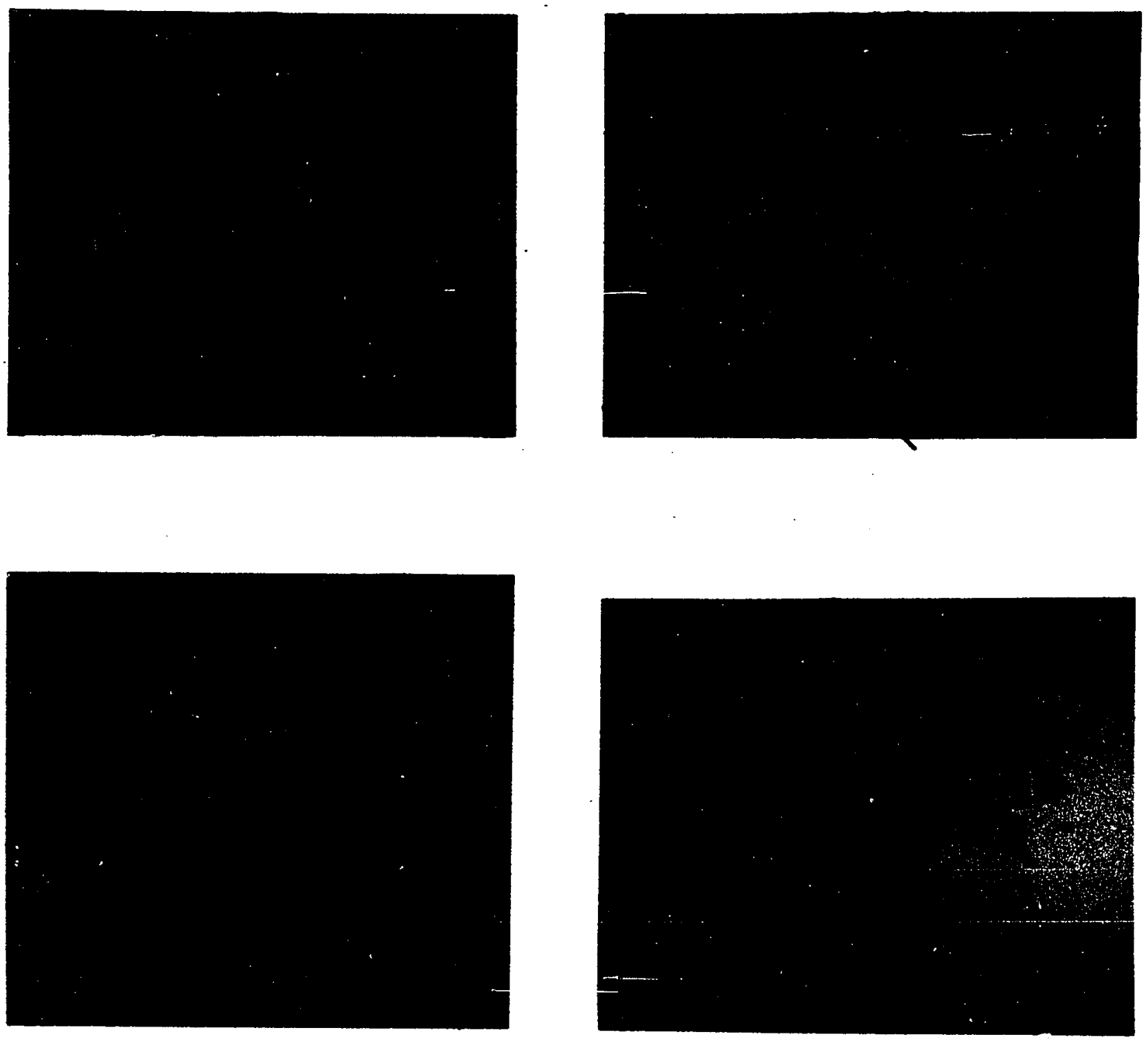

Flgux 22 

Figure 23. Illustrating possible independence of "tonic" and patterned information channels. (a) Hypothetical discharge patterns of two cells in response to patterned and tonic inputs. The patterned input excites the upper cell and inhibits the lower one. This pattern of response may be maintained over a wide range of tonic activity levels, which are assumed in this case to involve both cells equally. For cell populations which respond in this way, one may think of the tonic and patterned aspects of their activity as potentially independent channe1s, as represented in (b). 
(a)

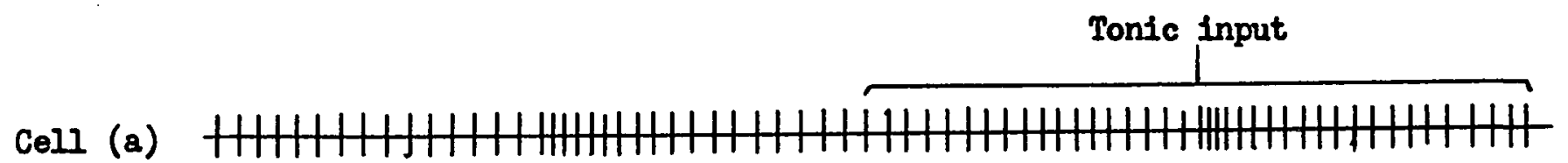

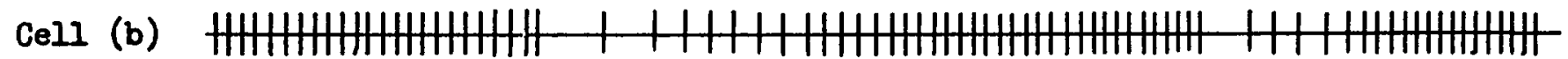

Patterned input

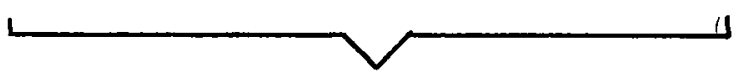

Summed impulses:

cell (a) 33

cell (b) 35

Both cells 68
39

46

85

(b)

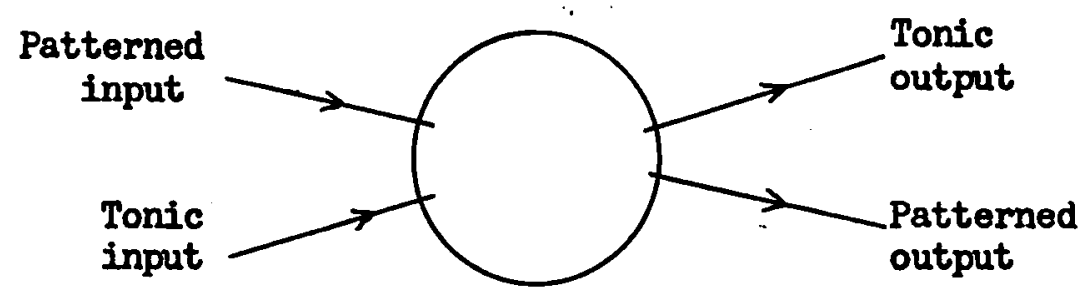

Figure 23 
APPENDIX

Interpretation of the Integrated Multi-unit Record

Arduini and Pinneo (1963) argue on theoretical grounds that the mean square or root-mean-square of a multi-unit signal is proportional to the number of nerve impulses per unit time in the immediate vicinity of the electrode tip. They also provide a discussion of the results of their studies of the visual system using this method, supporting their theoretical argument. Since they made the initial assumption, however, that impulses within the sampled population occurred randomly, questions may be raised concerning the influence on the integrated record of changes in neural firing patterns. In other studies of integrated activity, either no assumptions were made about the origin of the activity (e.g. Starr and Livingston, 1963), or it was assumed that the integrator output provided a measure of average neural discharge rates. (e.g. Buchwald et a1, 1966b). That this assumption is at least approximately true can be verified by inspection of parallel records of raw and integrated multi-unit records (Fig. 4).

Some evidence against the idea that the 
integrated record reflects patterned changes in activity is provided by the fact that the change in the patterns of unit activity in the cortex and reticular formation which occur when an animal goes to sleep are not reflected in the integrated multi-unit record. (See Discussion). 